\title{
Screen-printed electrodes for electroanalytical sensing of chromium VI in strong acid media
}

\author{
S. A. Miscoria ${ }^{1,2}$, C. Jacq ${ }^{3}$, T.Maeder $^{3 *}$, R. M. Negri ${ }^{1 * \dagger}$ \\ 1 Instituto de Química Física de los Materiales, Medio Ambiente y Energía (INQUIMAE). Departamento de \\ Química Inorgánica, Analítica y Química Física (DQIAyQF). Facultad de Ciencias Exactas y Naturales. \\ Universidad de Buenos Aires. Buenos Aires, Argentina. \\ 2 Departamento de Química. Facultad de Ciencias Naturales. Universidad Nacional de la Patagonia San \\ Juan Bosco. Comodoro Rivadavia, Chubut, Argentina. \\ 3 Laboratoire de Production Microtechnique (LPM), École Polytechnique Fédérale de Lausanne (EPFL), \\ CH-1015 Lausanne, Switzerland. \\ * Corresponding authors
}

Reference: Sensors and Actuators B 195, 294-302, 2041; http://dx.doi.org/10.1016/j.snb.2014.01.013

\section{Highlights}

- Acid-resistant screen-printed electrodes (SPEs) for Cr(VI) detection were developed.

- Carbon-based thick-film SPE pastes were formulated in-house with known composition.

- A batch fabrication process allowed simple fabrication of robust sensors.

- $\mathrm{Cr}(\mathrm{VI})$ at $\mathrm{pH} 1$ was electroanalytically quantified with high sensitivity.

- High reproducibility, wide linear range and low detection limit were achieved.

\section{Abstract}

Simple, low-cost and acid-resistant carbon-based screen-printed electrodes (SPEs) addressed to detection of hexavalent chromium species, $\mathrm{Cr}(\mathrm{VI})$, in sulfuric acid at $\mathrm{pH}$ about 1 , were prepared and characterized. Working and counter electrodes were prepared jointly on the same substrate in a single strip (working-counter electrodes pair). The batch printing process allowed obtaining many working-counter electrode pairs in a unique step. The developed working electrodes are comprised of several layers deposited on an alumina substrate: (1) bottom silver conductor, (2) dense organic-graphite composite conductor, (3) active layer consisting of a porous organic-graphite composite which contains a $\mathrm{Cr}$ (III) ionophore for testing $\mathrm{Cr}(\mathrm{III})$ obtained after reducing $\mathrm{Cr}(\mathrm{VI})$, and (4) an insulating and protective dielectric. All materials except the bottom Ag conductor were made on an organic matrix based on a thermoplastic polymer, polyvinylbutyral (PVB). The amperometric determination of $\mathrm{Cr}(\mathrm{VI})$ species at $\mathrm{pH} 1$ was performed over a wide concentration range (dynamic range $3 \mu \mathrm{M}-40 \mathrm{mM}$ ). The range for linear amperometric response is $3 \mu \mathrm{M}-10 \mathrm{mM}$, with sensitivity about $0.08 \mathrm{~mA} \mathrm{mM}^{-1}$. The sensitivity is improved in comparison with previously developed sensors, while keeping a low limit of detection (LOD about $1 \mu \mathrm{M}$ ). The response of the sensors are not interfered by the presence of $\mathrm{Cr}(\mathrm{III})$ in the solution, although the sensor can detect local formation of $\mathrm{Cr}$ (III) 
at the electrode surface after the reduction of $\mathrm{Cr}(\mathrm{VI})$ when diethylenetriamine-pentaacetic acid (DTPA), a complexing agent for Cr(III) is incorporated into the pastes.

\section{Keywords}

electrochemical sensors; hexavalent chromium; screen-printed electrodes ; thick-film technology.

\section{Abbreviations}

C18E2 : PEG-2 stearyl ether / steareth-2 / Brij S2

DTPA: Diethylenetriamine-pentaacetic acid

PVB: Polyvinylbutyral

SPE: Screen-printed electrodes

DMSO: Dimethylsulfoxide

\section{Introduction}

Detection of chromium (VI) species in natural environments (referred generically as $\mathrm{Cr}(\mathrm{VI})$ ) represents an issue of high relevance in environmental control because of the high toxicity and solubility of $\mathrm{Cr}(\mathrm{VI})$ compounds in comparison with chromium species in other oxidation states (Cr(III), $\mathrm{Cr}(\mathrm{II})$ ) [1-9]. Cr(VI) species have mutagenic, genotoxic and carcinogenic effects on humans and animals, and its main sources are plating industries, leather tanning, wood preservation and electricity generation, which use large amounts of $\mathrm{K}_{2} \mathrm{Cr}_{2} \mathrm{O}_{7}$ that are eliminated in acid effluents [2,10-13]. Remediation includes chemical treatments and bioremediation processes; e.g. the group at INQUIMAE have recently monitored the growth of acidophilic bacteria Acidithiobacillus thioxidans (AT), used in $\mathrm{Cr}$ (VI) bioremediation by means of electronic noses coupled to bioreactors in acid media $(\mathrm{pH} \leq 1)[14]$. AT is a chemolithotrophic bacteria used for biotechnological leaching and heavy metal bioremediation, grown in air-lift bioreactors using tiny bits of elemental sulfur as energy source, where the biofilms grow by oxidation of elemental sulfur to sulfate in a process that increases the acidity of the medium [15] and [16]. For instance, in the bioreactors implemented at INQUIMAE, $\mathrm{pH}$ decreases from 3 to 0 in few days during the phase of biofilm growth, depending of the conditions [14].

Hence, there is large interest for monitoring $\mathrm{Cr}(\mathrm{VI})$ at $\mathrm{pH} \cong 0-1$ in sulfuric acid, for instance when using chemolithotrophic bacteria in bioremediation process used in the described bioreactors or when monitoring very acid effluents, such as those used in leather tanning and plating industries (which commonly use sulfuric acid media at $\mathrm{pH} \cong 0-1$ also). 
In all the mentioned cases, after dissolution of $\mathrm{K}_{2} \mathrm{Cr}_{2} \mathrm{O}_{7}$ at $\mathrm{pH}<2$, chromium remains as $\mathrm{Cr}(\mathrm{VI})$, the main species at those $\mathrm{pH}$ values being $\mathrm{HCrO}_{4}{ }^{-}$and $\mathrm{H}_{2} \mathrm{CrO}_{4}$ [13]. In the industrial effluents, before remediation, the concentrations of these species are between 0.1 and $10 \mathrm{mM}$. These concentrations are higher than the limit recommended by the World Health Organization (WHO) for drinking water, $1 \mu \mathrm{M}$ [8], thus effluents require pretreatments and exhaustive monitoring (see also reference [2]). Since the pioneer works of Urone [17] and [18] the more common technique for quantifying $\mathrm{Cr}(\mathrm{VI})$ in solution is spectrophotometric based on the formation of the colored complex between chromium and 1,5-diphenylcarbazide (DPC), performed at $\mathrm{pH}$ 1. Atomic absorption spectrometry and inductively coupled plasma mass spectrometry are the latest designs [19-26]. In general, previous treatment of samples involving preconcentration and separation schemes is required, such as chromatography, precipitation, extraction, etc. Additionally, turbidity of the samples, difficulties of handling, the unfeasibility to measure on time and the cost of operation and spectroscopic devices for in situ determinations, represent significant drawbacks.

Alternatively, electrochemical techniques are always interesting alternatives as they offer a rapid detection of the analyte in different matrices because they do not require prior separation and can be used in the presence of turbidity. Adsorptive stripping voltammetric methods have been reported. Jorge et al. [27] presented an adsorptive stripping voltammetric protocol coupled with a rotating disc bismuth film electrode obtaining very low limit of quantification (LOQ), in the range of $\mathrm{nM}$, but at $\mathrm{pH} 4.6$, acetate buffer. Lin et al. [28] described an adsorptive stripping voltammetric protocol at a bismuth-coated glassycarbon electrode for trace measurements of chromium (VI) for $\mathrm{pH}$ between 4.5 and 7.5. Grabarczyk [29] developed a procedure based on a quantitative extraction method to extract total $\mathrm{Cr}(\mathrm{VI})$ (soluble and insoluble forms) from a solid sample, detecting $\mathrm{Cr}(\mathrm{VI})$ in the extract by a catalytic adsorptive stripping voltammetric technique for $\mathrm{pH}$ between 5 and 6 .

On the other hand, concerning solid-state sensors coupled to amperometric or voltammetric detection, Bergamini et al. [30] and Sanchez-Moreno et al. [31] reported detection of $\mathrm{Cr}$ (VI) at $\mathrm{pH} 2$ and 3. Fiol et al. [32] prepared vegetable waste-based sensors with selectivity for $\mathrm{Cr}(\mathrm{VI})$ and $\mathrm{Hg}(\mathrm{II})$ for $\mathrm{pH}$ 2-3 with $\mathrm{LOD}$ about $2 \mathrm{mM}$ and sensitivity of $-61 \mathrm{mV} /$ decade. In these works the experiments were performed at $\mathrm{pH} \geq 2$. Other authors developed relatively more sophisticated modified electrodes. For instance, Svancara et al. [33] reported $\mathrm{Cr}(\mathrm{VI})$ sensor working at $\mathrm{pH}$ between 1 and 3 based on synergistic preconcentration of the chromate anion at a carbon paste electrode modified in situ with quaternary ammonium salts. Hallam et al. [34] described screen printed electrodes (SPE) with platforms based on graphite for $\mathrm{Cr}(\mathrm{VI})$ sensors, working at $\mathrm{pH} 1$ obtaining a limit of detection (LOD) about $0.4 \mu \mathrm{M}$, a limit of quantification (LOQ) of $2 \mu \mathrm{M}$, but in short range for linear response (up to $20 \mu \mathrm{M}$ ). Welch et al. [13] found that $\mathrm{Cr}(\mathrm{VI})$ in $\mathrm{pH} 1$ solutions can undergo chemically irreversible reduction on the surface of diamond electrodes, doped with gold, glassy carbon and boron with an LOD of $4 \mu \mathrm{M}$. 
Thus, there is continuous interest to develop low-cost, serial fabricated and robust sensors, for detection and quantification of $\mathrm{Cr}(\mathrm{VI})$ species in $\mathrm{pH} \leq 1$

Screen-printed electrodes (SPE) represent a highly interesting option when considering technological aspects related to mass production, including improvements in reproducibility and replicability, low costs and size reduction. Coupling these aspects with the general advantages of electroanalytical detection appears attractive for environmental monitoring of acid effluents containing $\mathrm{Cr}(\mathrm{VI})$. High sensitivity, excellent limits of detection, no requirements concerning large sample volume and possibilities for analyzing turbid media are relevant characteristics of SPE sensors.

However development and application of fully-integrated screen-printed electrodes (for instance integrating working, counter and reference electrodes) for $\mathrm{Cr}(\mathrm{VI})$ detection in acid media ( $\mathrm{pH} \approx 1$ ) had not been achieved yet. Actually, application of screen printed working electrodes for $\mathrm{Cr}(\mathrm{VI})$ detection and quantification has been reported in very few cases and at higher $\mathrm{pH}$ values [29-31] and [35]. The challenges lie in the formulation of screenprintable inks compatible with processing at moderate temperatures, for obtaining acidresistant electrodes that allow working at $\mathrm{pH} \leq 1$, with an active surface tailored to achieve selective response to Cr(VI) under these conditions. Ideally, the three electrodes (working, counter and reference) should be integrated into a single device.

Screen-printed thick-film sensors, as previously developed [36-38], provide an ideal platform for realizing such an SPE. Hence, the aims of the present work, originated in a preliminary conference paper [39], are to present the steps of the fabrication process and the quality parameters of the obtained sensors. The SPE graphite electrodes for $\operatorname{Cr}(\mathrm{VI})$ quantification were fabricated by integrating working and counter electrode into a unique strip. These systems proved very highly robust in acid media, with the possibility of recording amperometric signals at two different potentials.

\section{Material and methods}

\subsection{Reagents}

$\mathrm{K}_{2} \mathrm{Cr}_{2} \mathrm{O}_{7}$ was from Anedra and $\mathrm{H}_{2} \mathrm{SO}_{4}$ from Cicarelli (Argentina, analytical grade). Millipore-MilliQ water $(\rho=18 \mathrm{M} \Omega \cdot \mathrm{cm})$ was used for preparing the solutions. All chemicals were reagent grade and used without further purification. The silver ink (Ag, type 9912K) was from ESL, ElectroScience Laboratories, USA. Polyvinylbutyral (PVB), acetyltributylcitrate (ATBC), cetanol, steareth-2 (C18E2) and diethylenetriaminepentaacetic acid (DTPA) were from Sigma-Aldrich. Synthetic graphite powder was KS4 from TIMCAL (ovaloid shape, $\leq 4 \mu \mathrm{m}$ ). Detailed information on the materials used for the SPEs is given in supplement $\mathbf{S} 1$. 


\subsection{Apparatus}

Amperometric measurements and cyclic voltammetry experiments were performed with a Potentiostat/Galvanostat Teq3 Analyzer (Argentina). The electrodes were inserted into an electrochemical cell (BAS, Model MF 1084) through its Teflon cover. The reference was a $\mathrm{Ag} / \mathrm{AgCl}, 3 \mathrm{M} \mathrm{NaCl}$ (BAS, Model RE-5B) electrode and all the potentials are referred to that. The set up is similar to those described in previous work $[40,41]$ Scanning electron microscope (SEM) images were obtained with a field Emission Scanning Electron Microscope, Zeiss Supra 40 Genimi.

\subsection{Electrode Preparation}

\subsubsection{Fabrication of the electrodes}

Figure 1 shows a layout of the screen-printed electrodes (Figure 1A) and the ink depositions steps (Figure 1B) (more details are given in Supplements S2 (cross section) and S3 (substrate)). The electrodes, which have a convenient elongated shape, were batch fabricated on $96 \%$ alumina substrates $\left(\mathrm{Al}_{2} \mathrm{O}_{3}\right.$, standard thick-film grade) by screen printing and thermal processing of thick-film inks [42]. The complete materials stack is given in Table 1. Dense (to completely cover the Ag layer) and porous (to allow intimate contact with the solution) carbon pastes were subsequently deposited on the working electrode, Except the first layer (thick-film silver, $\mathrm{Ag}$ ), which was fired at $10 \mathrm{~min}$ peak dwell at $850^{\circ} \mathrm{C}$ in a belt furnace, thermal processing of the other layers simply involved evaporating the solvent, with a typical cycle of 10 minutes at $120^{\circ} \mathrm{C}$ in a ventilated oven. The nominal (geometric) area of the working electrode was $4.0 \mathrm{~mm} \times 6.0 \mathrm{~mm}$.

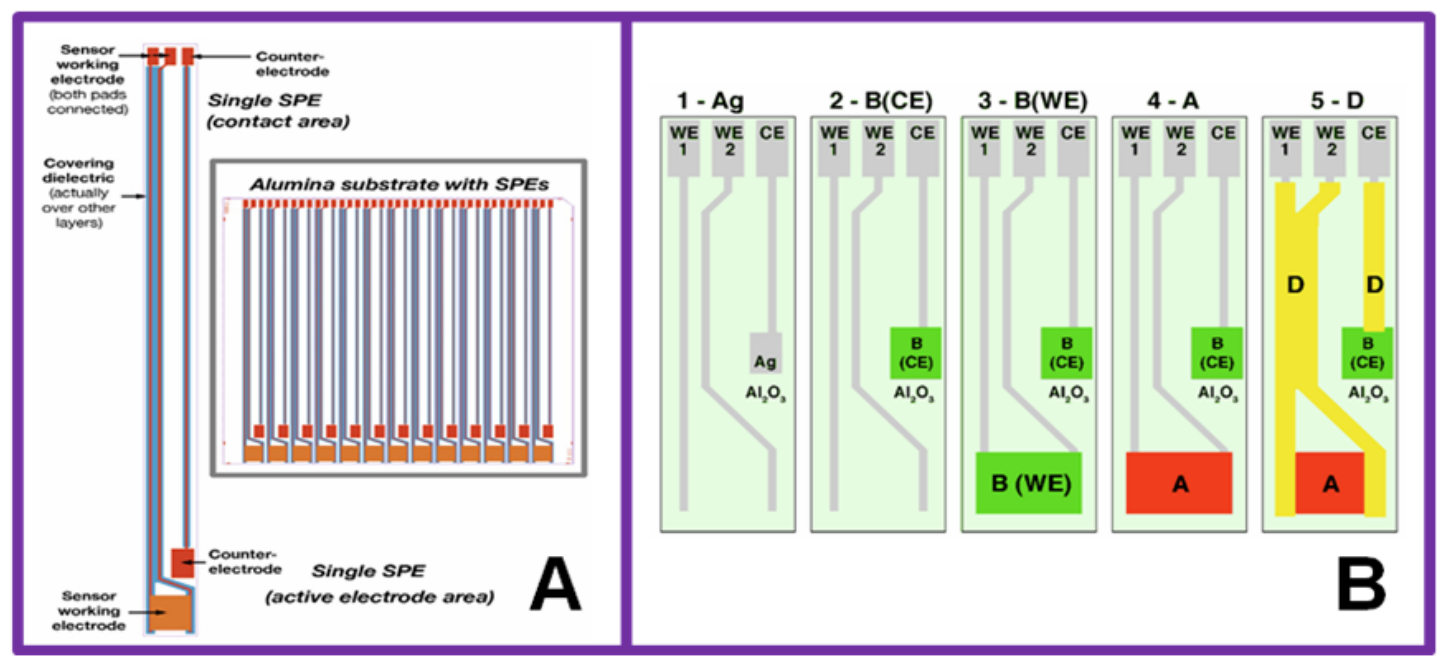

Figure 1. (A): Layout of SPEs, single bar and as complete substrate for batch printing on alumina (inset). Layers according to Table 1; conductors in contact with solution: dense polymer-KS4 composite (both working electrode $\&$ counter electrode), and porous polymer-KS4-DTPA (working only). (B): Ink deposition steps: (1) Ag conductor; (2,3) Dense polymer-graphite (B) for counter (CE) and working (WE) electrode; (4) Porous, polymer-graphite-ionophore active layer; (5) Protective dielectric. 
Table 1. Thick-film compositions used in the fabrication of the SPEs based on PVB binder (Figure 1).

\begin{tabular}{ll}
\hline Layer & Composition (see supplement S2) \\
\hline Ag conductor tracks \& contact pads & ESL 9912K \\
Dense carbon layer (KS4 $\approx 33 \%$ vol.) & PVB - ATBC - KS4 \\
Porous active carbon layer (KS4 $\approx 70 \%$ vol) & PVB - ATBC - KS4 - DTPA \\
Protective dielectric & PVB - cetanol - C18E2/ATBC \\
\hline
\end{tabular}

The working electrode was fabricated with two pads in order to measure the conductivity of the graphite paste layer after the whole process when testing different pastes based on different polymers (later, those pads were short circuited). Because of the aim of this first work of the joint groups was to obtain the appropriated paste and to define the whole fabrication protocol in order to produce series of sensors with good quality parameters, the system presented here integrates only the working and counter electrode, but not the reference electrode, since to fabricate series of fully integrated systems (with the three electrodes) requires to set additional conditions, which are being adjusted at present.

\subsubsection{Formulation of the screen-printing inks}

Except the first silver (Ag) conductor layer, all inks were formulated and prepared in-house (Table 1) as screen-printing pastes, based on polyvinylbutyral (PVB) plasticized by acetyltributylcitrate (ATBC), dissolved in appropriate high-boiling solvents (see Supplement S1). These starting mixtures serve both as screen-printing vehicles and, after evaporation of the solvent, as organic matrices. For electrode materials, synthetic graphite powder KS4 from TIMCAL was used as the conductive phase, with the degree of porosity being set by changing the ratio between graphite and matrix (PVB + ATBC). PVB was chosen over more standard ethylcellulose (EC) because its carbon backbone is not sensitive to acid hydrolysis (as it is for EC [43]; see also Supplement S4). Additionally, diethylenetriamine-pentaacetic acid (DTPA), a $\mathrm{Cr}$ (III) ionophore [42] and [45] was incorporated into the vehicle of the active sensing electrode ink by first dissolving it (15\% mass) into dimethylsulfoxide (DMSO) and subsequently adding this resulting solution. The presented results correspond to samples with $4.7 \%(\mathrm{w} / \mathrm{w})$ DTPA in the ink, although samples with DTPA varying from $2.0 \%(\mathrm{w} / \mathrm{w})$ to $8.5 \%(\mathrm{w} / \mathrm{w})$ were tested. Increased DTPA concentration corresponded to decreased binder and plasticizer content, with KS4 (conductive filler) content somewhat increased to maintain printable rheology (see Table $\mathbf{S 1}$ in supplement). These changes led to small variations in the sensor response which do 
not change the main conclusion and results presented here. The protective dielectric layer was prepared by incorporating cetanol and C18E2 (steareth-2) into the base formulation. Upon drying and cooling, these waxes crystallize out of the PVB + ATBC matrix to yield a tough, hot-melt chemically resistant layer. For comparison purposes, samples with two layers (dense carbon and dielectric) based on an epoxy matrix instead of PVB were also fabricated (Supplement S5).

Figure 2 shows a photograph of two sensors $\left(101.6 \times 7 \mathrm{~mm}^{2}\right)$ along a $\mathrm{cm}$ ruler. Figure $3 \mathrm{~A}$ shows a SEM image of the graphite screen printed electrochemical sensor where a welldefined electrode surface is observed from randomly orientated graphite particles bound together with the inert polymeric binder. This layer sits on the dense carbon conductor (Figure 3).

\subsection{Electroanalytical measurements}

Cyclic voltammetries and amperometric experiments were performed in a three electrodes electrochemical cell at $(25 \pm 1){ }^{\circ} \mathrm{C}$. Solutions were under permanent agitation provided by a magnetic stirrer during the amperometric determinations. The support electrolyte was sulfuric acid $\left(\mathrm{H}_{2} \mathrm{SO}_{4}\right)$. The amperometric measurements were carried out by applying the desired potential and allowing the transient current to decay up to a plateau prior to the addition of $\mathrm{Cr}(\mathrm{VI})$ and the subsequent current monitoring.

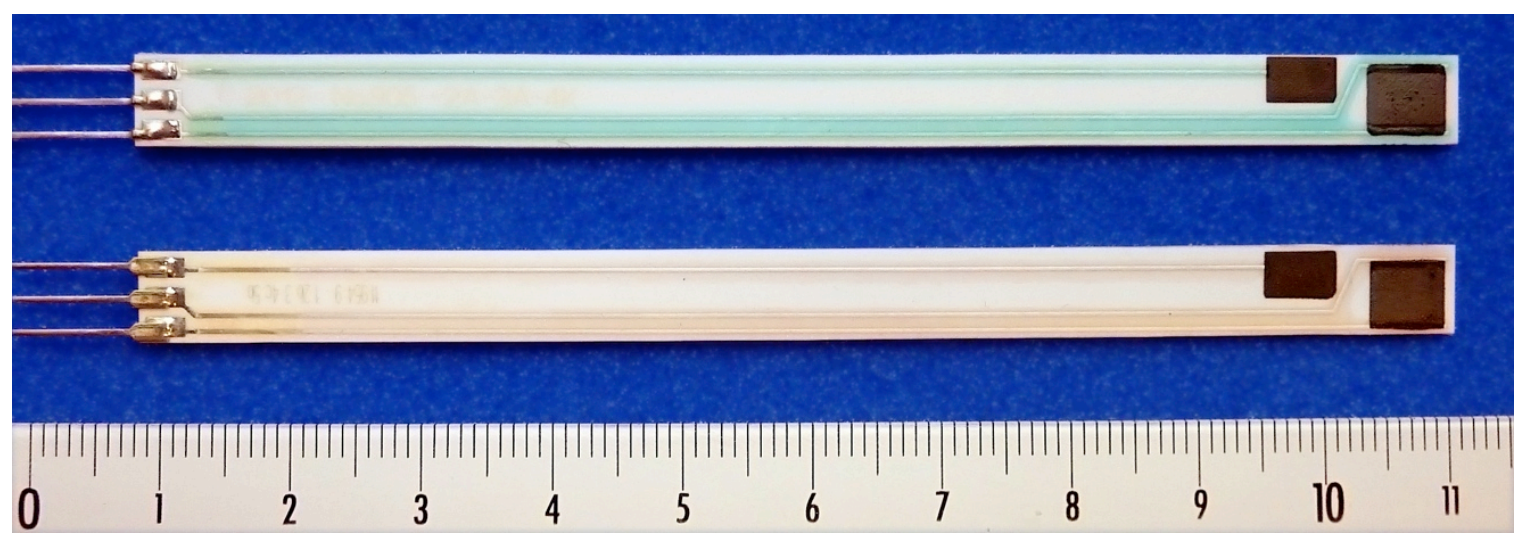

Figure 2: Photograph of two sensors $\left(101.6 \times 7.0 \mathrm{~mm}^{2}\right.$, ruler in $\left.\mathrm{cm}\right)$. 


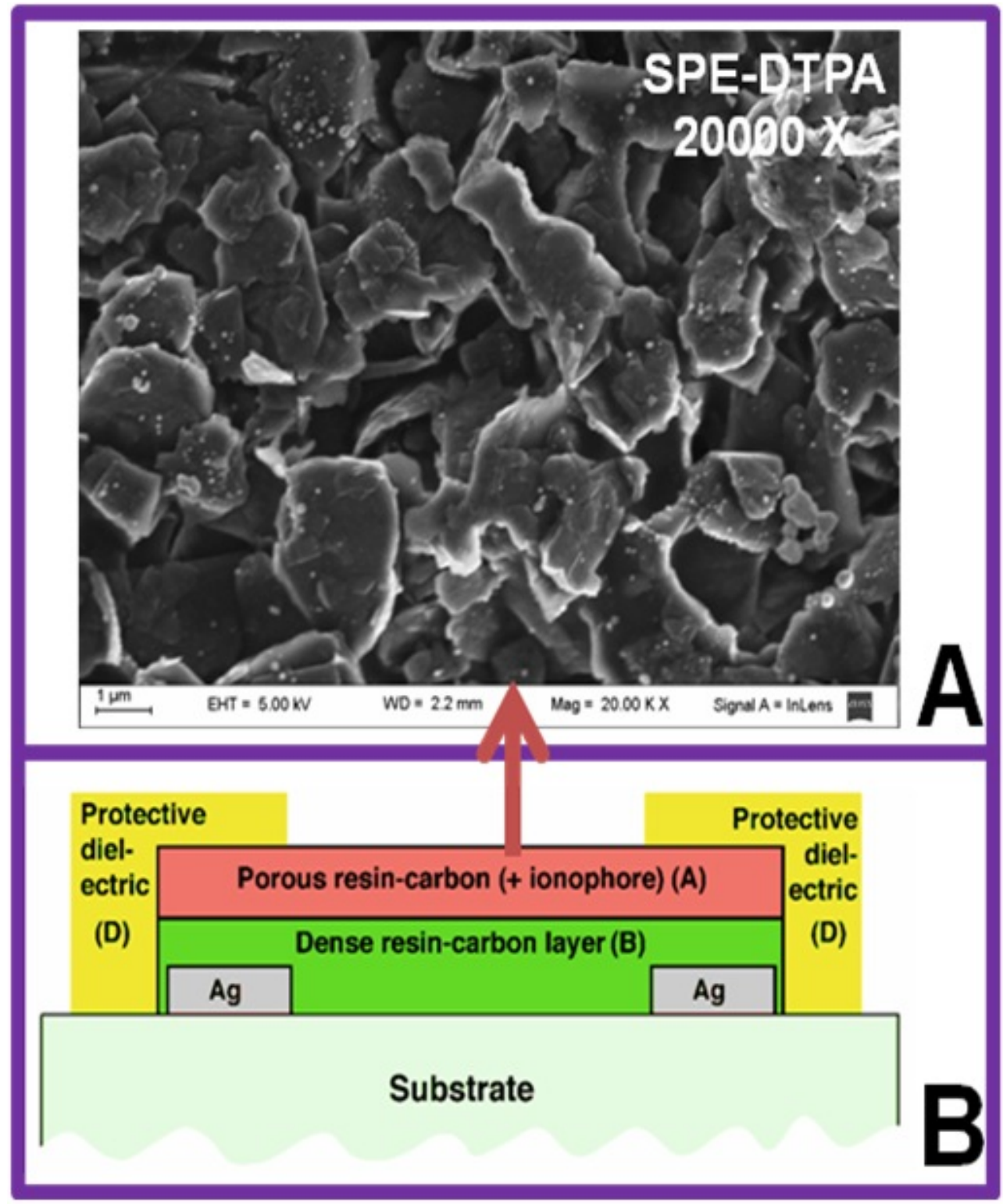

Figure 3 (A): Scanning electronic microscopy pictures of PVB-DTPA-based system by magnification $20000 \mathrm{X}$. (B) for WE; 5) insulating dielectric (D) to insulate Ag from the electrolyte. (B): Cross section of the active electrode (expanded vertical scale). The counter electrode is similar, but without the porous active layer. 


\section{Results and Discussion}

Two types of measurements were performed: (1) cyclic voltammetries varying scan rates, (2) amperometries at fixed voltages by successively adding concentrated aliquots of $\mathrm{K}_{2} \mathrm{Cr}_{2} \mathrm{O}_{7}$ in $\mathrm{H}_{2} \mathrm{SO}_{4}$, adjusted to obtain the desired concentration.

\subsection{Voltammograms}

Figure 4 shows cyclic voltammograms obtained at $50 \mathrm{mV} \cdot \mathrm{s}^{-1}$ for a PVB-SPE containing $4.7 \% \mathrm{w} / \mathrm{w}$ of DTPA in oxygenated solutions of $\mathrm{H}_{2} \mathrm{SO}_{4} \mathrm{pH}: 1.0$. The scans were performed from $+1000 \mathrm{mV}$ to $-1000 \mathrm{mV}$ to return finally to the initial potential. Figure 4A illustrates the irreversibility of the electrode process and the presence of shoulders with maxima at about $+150 \mathrm{mV}$ and $-370 \mathrm{mV}$ (although the exact position of both peaks has a slight dependence on $\mathrm{K}_{2} \mathrm{Cr}_{2} \mathrm{O}_{7}$ concentration). Figure $4 \mathrm{~B}$ shows a zoom for potentials between $\pm 600 \mathrm{mV}$ and concentrations lower than $1.0 \mathrm{mM}$ in steps of $0.1 \mathrm{mM}$ (only the reduction window is shown for a better visualization).

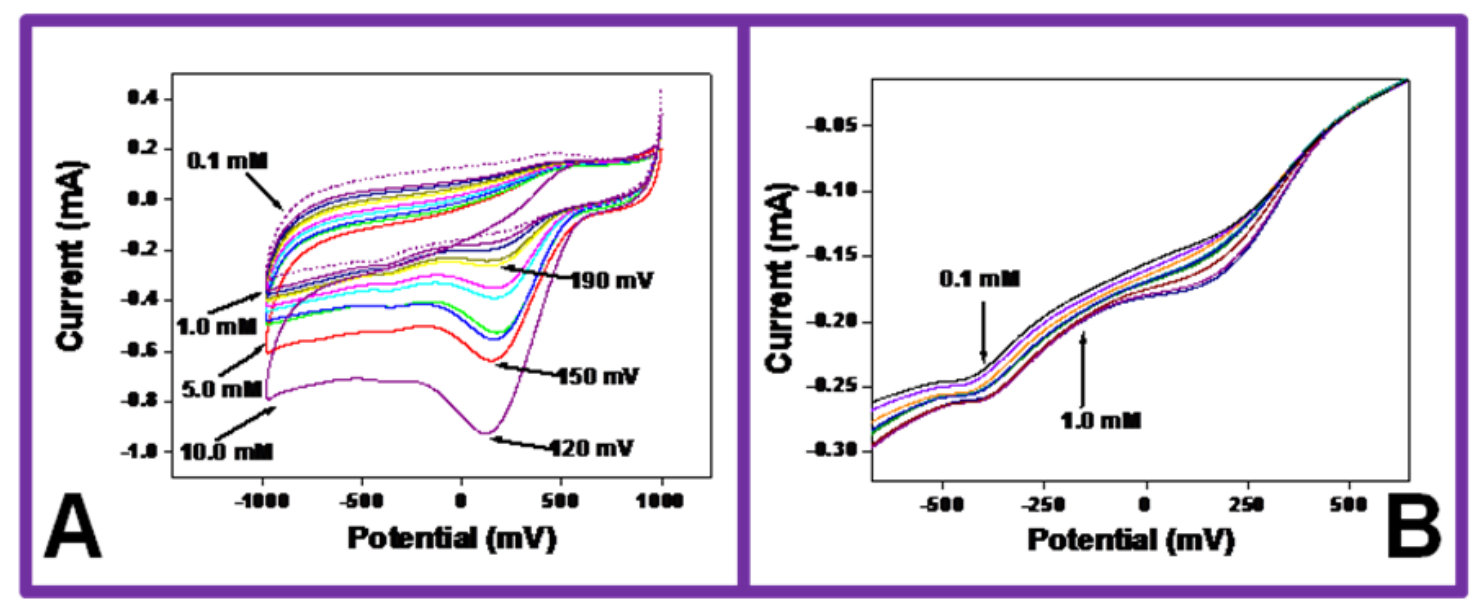

Figure 4. Cyclic voltammograms for $\mathrm{Cr}(\mathrm{VI})$ (A): at different concentrations, from $1.0 \mathrm{mM}$ to $5.0 \mathrm{mM}$ with $0.5 \mathrm{mM}$ breaks, (the curves for $0.1 \mathrm{mM}$ and $10 \mathrm{mM}$ are also included). The scans were performed from $1000 \mathrm{mV}$ to $-1000 \mathrm{mV}$ to return finally to the initial potential. (B): zoom for potentials between ($600,600) \mathrm{mV}$ and concentrations lower than $1.0 \mathrm{mM}$ in steps of $0.1 \mathrm{mM}$. A peak at $-370 \mathrm{mV}$ is observed. Scan rate: $50 \mathrm{mV} / \mathrm{s}$. Supporting electrolyte: $\mathrm{H}_{2} \mathrm{SO}_{4} \mathrm{pH}$ : 1.0. Reference electrode: $\mathrm{Ag} / \mathrm{AgCl}$. Counter electrode: graphite. 
Figure 5 shows a logarithmic relationship between the peak voltage, $V \mathrm{p}$, and peak current, $I_{\mathrm{p}}$, for different concentrations of $\mathrm{K}_{2} \mathrm{Cr}_{2} \mathrm{O}_{7}$ (and for the positive voltages). The value of $V_{\mathrm{p}}$ remains almost constant $(+150 \mathrm{mV})$ for concentrations lower than $1 \mathrm{mM}$. Nevertheless, $V_{\mathrm{p}}$ deceases for higher concentrations, observing a linear relation relationship between $V_{\mathrm{p}}$ and $I_{\mathrm{p}}$ for concentrations between 1 and $10 \mathrm{mM}$. In the case of a reversible process, commonly used electrochemical models predict that $V_{\mathrm{p}}$ must be independent of the analyte concentration, but those models do not apply for irreversible systems. Thus, the decrease of $V_{\mathrm{p}}$ when increasing $\mathrm{Cr}$ (VI) concentration (at a fixed scan rate) seems to be related to the irreversible behavior of the electrodes (a complete understanding of the $V_{\mathrm{p}}$ vs. $I_{\mathrm{p}}$ relationship is beyond the scope of the present work).

\subsection{Scan rate experiments}

Scan rate studies were performed in the absence of stirring. It was observed that the position of the reduction peak shifts towards more negative values with increasing the scan rate, in agreement with the irreversible behavior shown in Figure 4A. The dependence of the current peak with the scan rate is given in Fig. 6 for $+150 \mathrm{mV}$ (Fig. 6A) and $-370 \mathrm{mV}$ (Figure 6B). The scans were performed from $+1000 \mathrm{mV}$ to $-1000 \mathrm{mV}$ and returning finally to the initial potential. The linear relationship between current peak (at +150 and $-370 \mathrm{mV}$ ) and the square root of the scan rate indicates that signals are the resultant of a diffusioncontrolled process.

Summarizing the scan-rate experiments, it is concluded that the response of the sensor is associated to irreversible processes that are kinetically controlled by diffusion of the analyte towards the surface and not by its adsorption or the consequent reduction.

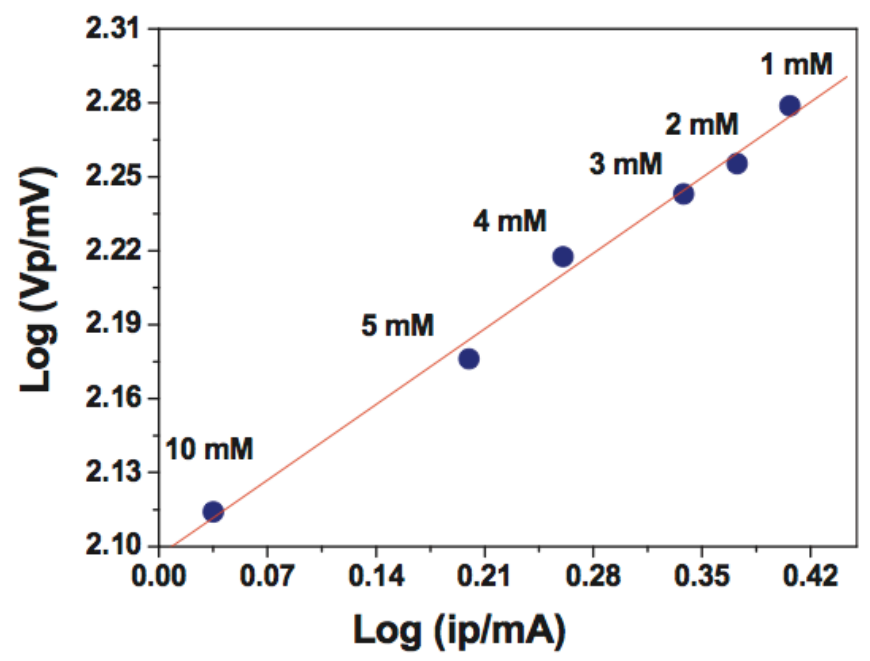

Figure 5. $\log \left(V_{\mathrm{p}} / \mathrm{mA}\right)$ vs. $\log (\mathrm{Ip} / \mathrm{mV})$ (taken from Figure 4 for the peak at positive voltages (vs. $\left.\mathrm{Ag} / \mathrm{AgCl}\right)$ for different concentration of $\mathrm{K}_{2} \mathrm{Cr}_{2} \mathrm{O}_{7}$ in $\mathrm{H}_{2} \mathrm{SO}_{4}$, $\mathrm{pH} 1$. 


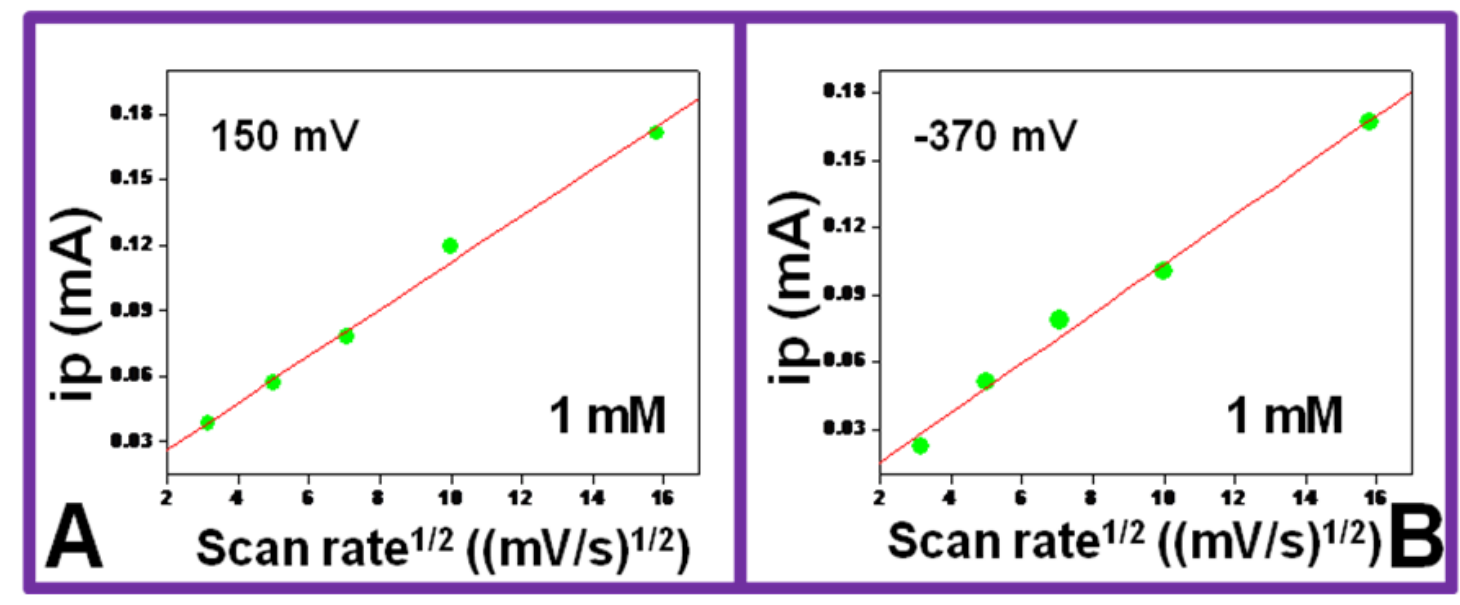

Figure 6. Reduction peak currents (A): at $150 \mathrm{mV}$, (B): at $-370 \mathrm{mV}$ versus its scan rate square root, obtained from the cyclic voltammograms for $1 \mathrm{mM}$ of $\mathrm{Cr}(\mathrm{VI})$. The scans were carried out from $1000 \mathrm{mV}$ to $-1000 \mathrm{mV}$ to return finally to the initial potential. Supporting electrolyte: $\mathrm{H}_{2} \mathrm{SO}_{4} \mathrm{pH} \mathbf{1 . 0}$. Reference electrode: Ag/AgCl. Counter electrode: graphite.

\subsection{Origin of the analyzed peaks}

The first peak correspond to a broad band that begins at about $+450 \mathrm{mV}$ (depending on the $\mathrm{Cr}(\mathrm{VI})$ concentration) when decreasing the voltage from $+1000 \mathrm{mV}$. This band is reasonable assigned to reduction of $\mathrm{Cr}(\mathrm{VI})$ to lower oxidation states, since current decreases and there are not higher oxidation states available.

The presence of DTPA is irrelevant in the observation of the band centered at $+150 \mathrm{mV}$ since the apparition of that band was verified (and peak) when using working electrodes prepared without DTPA (the experimental conditions remaining the same). Thus, as already reported in other cases $[13,34]$, no need for $\mathrm{Cr}(\mathrm{VI})$ ionophore is required: the surface provides the conditions for the reduction. In agreement, the band centered at $+150 \mathrm{mV}$ do not appears when only $\mathrm{Cr}(\mathrm{III})$, but not $\mathrm{Cr}(\mathrm{VI})$, is present $\left(\mathrm{CrCl}_{3} \cdot n \mathrm{H}_{2} \mathrm{O}\right.$ was used). Therefore, we conclude that the surface donates the electrons for $\mathrm{Cr}(\mathrm{VI})$ reduction for voltages lower than approximately $+475 \mathrm{mV}$ (the voltages are always referred to $\mathrm{Ag} / \mathrm{AgCl}$ reference electrode).

On the other hand, the band centered at $-370 \mathrm{mV}$ is assigned to the subsequent reduction of the $\mathrm{Cr}(\mathrm{III})$ formed at the surface when reducing $\mathrm{Cr}(\mathrm{VI})$. This is strongly suggested by observing that the peak at $-370 \mathrm{mV}$ only appears when using pastes containing DTPA, a well-known ionophore for selective determination of $\mathrm{Cr}$ (III) [44,45]. The formation of a $\mathrm{Cr}(\mathrm{III})-\mathrm{DTPA}$ complex has been proposed as participating in the reduction of $\mathrm{Cr}(\mathrm{III})$ where 
DTPA acts as chelating agent. After forming the complex on the surface, its reduction on the electrode surface causes the observed reduction peak. It is worth to remark that this peak has much lower intensity than the peak at $+150 \mathrm{mV}$, in agreement with the hypothesis that the signal at $-370 \mathrm{mV}$ is originated in a secondary process. The relative low intensity at $-370 \mathrm{mV}$ is related also to the fact that the fraction of DTPA available for chelating is restricted by two factors: a) at $\mathrm{pH}<1 \mathrm{DTPA}$ appears mainly as protonated $(\mathrm{pKa}=1.8)$ thus deactivating its chelating ability; b) most of DTPA molecules are inside the paste but not exposed to the electrode surface. As a matter of fact, no clear peaks were observed in the voltamogramms of $\mathrm{CrCl}_{3} \cdot n \mathrm{H}_{2} \mathrm{O}$ solutions.

Therefore, the hypothesis for describing the behavior of the electrodes presented in this work when introducing $\mathrm{K}_{2} \mathrm{Cr}_{2} \mathrm{O}_{7}$ is summarized as follows: the primary process is reduction of $\mathrm{Cr}(\mathrm{VI})$ to $\mathrm{Cr}$ (III) (and probably to lower states also). The reduction of $\mathrm{Cr}(\mathrm{VI})$ is provided by the surface (except the voltage is higher than $+450 \mathrm{mV}$ ) without need of any ionophore. Then a surface Cr(III)-DTPA complex is formed whose reduction is observed at lower voltages, i.e. $-370 \mathrm{mV}$. The amperometric analysis fixing the voltage at $-380 \mathrm{mV}$ can be also used for monitoring $\mathrm{Cr}(\mathrm{VI})$ since the primary process that allows the peak at $-380 \mathrm{mV}$ to be observed is $\mathrm{Cr}(\mathrm{VI})$ reduction by the surface.

\subsection{Quality parameters of the amperometric signal at $\pm 140 \mathrm{mV}$}

The sensitivity, limit of detection, robustness, response times, etc., of the sensors for detecting and quantifying $\mathrm{Cr}(\mathrm{VI})$ was determined by amperometric experiments instead of voltammograms, observing the effect of successive concentration increments on the detected current at fixed voltage, as illustrated in the following paragraphs (calibration plots obtained from voltammograms are much noisier and presents linearity only below $1 \mathrm{mM}$ ).

Figure 7A. and $\mathrm{C}$ shows amperometric recordings obtained from an experiment performed by successive additions of $\mathrm{K}_{2} \mathrm{Cr}_{2} \mathrm{O}_{7}$ in $\mathrm{H}_{2} \mathrm{SO}_{4} \mathrm{pH}$ : 1.0, fixing the voltage of the working electrode at $140 \mathrm{mV}\left(10 \mathrm{mV}\right.$ lower than the value of $V_{\mathrm{p}},+150 \mathrm{mV}$, in the considered concentration range).

The rise time of the signal after injection is $2-3 \mathrm{~s}$ for all concentrations. The time required for amperometric signal stabilization is dependent on the $\mathrm{K}_{2} \mathrm{Cr}_{2} \mathrm{O}_{7}$ concentration: it takes 5$10 \mathrm{~s}$ for concentrations below $1 \mathrm{mM}$, but can take 3-5 min for concentrations between 6 and $40 \mathrm{mM}$.

The momentary dips in current observed for some additions in Figure 7A and $\mathrm{C}$ are sometimes referred as "injection noise". The origin of that noise is the difficulties for injecting the analyte solution in the electrochemical cell, particularly when its dimensions are relatively small (volume of the solution, 30-50 $\mathrm{mL}$, approximately). It has a purely mechanical origin and does not disturb the amperometric response, which is stabilized after few seconds (injection is always performed under stirring). 


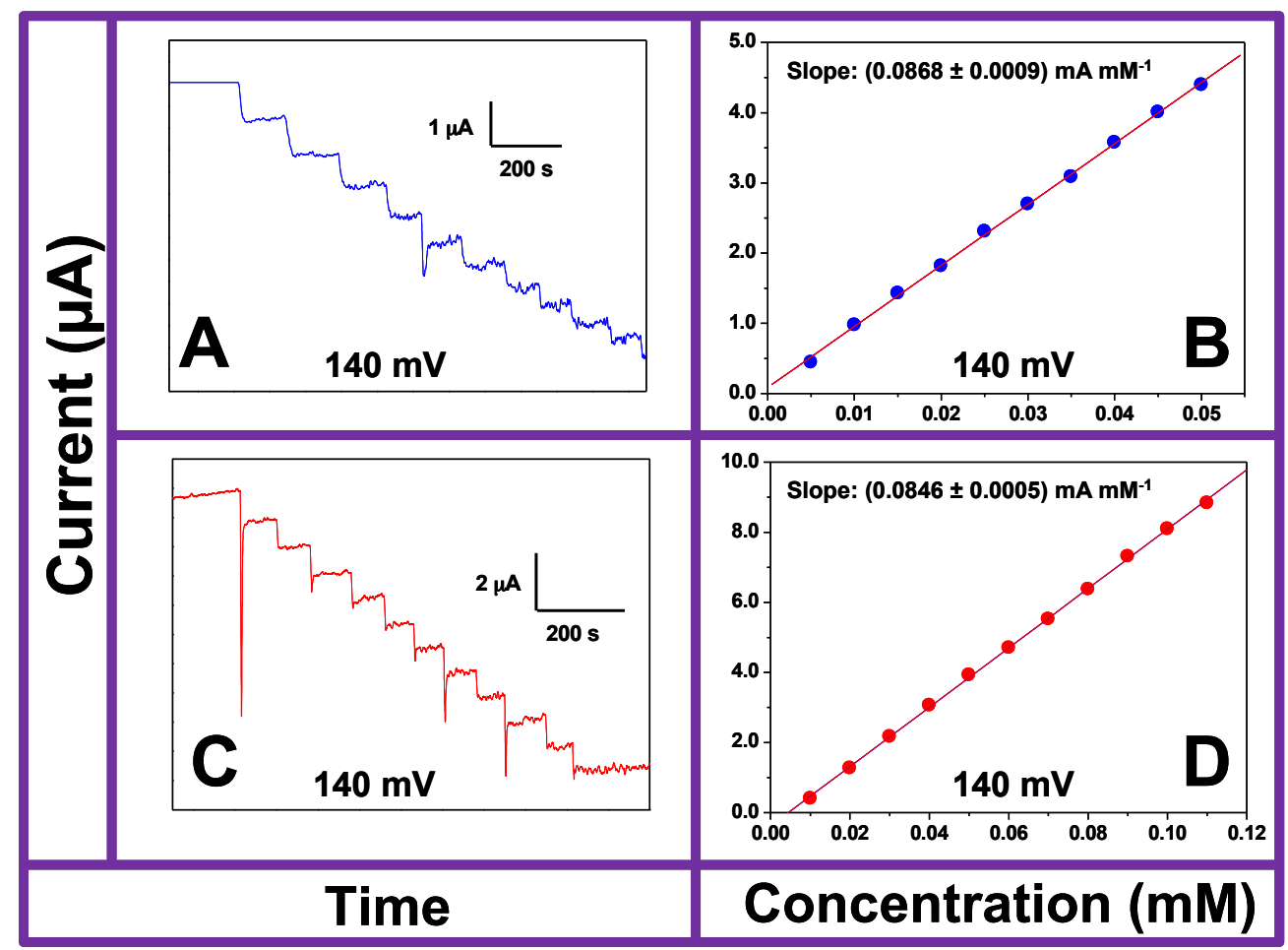

Figure 7. Amperometric recordings ( $A$ and $C$ ) and calibration plots ( $B$ and $D$ ) obtained from experiments performed by successive additions of $0.005 \mathrm{mM}(\mathrm{A}$ and $\mathrm{B})$ and $0.1 \mathrm{mM}$ (C and $\mathrm{D}) \mathrm{Cr}(\mathrm{VI})$, at $+140 \mathrm{mV}$. Supporting electrolyte: $\mathrm{H}_{2} \mathrm{SO}_{4} \mathrm{pH}$ : 1.0. Reference electrode: Ag/AgCl. Counter electrode: graphite.

Reproducibility test on a given electrode, different freshly made electrodes in the same batch (12 electrodes) and inter-batches were performed. The typical relative standard deviation (RSD) value in all cases was about 3-5\% (depending of the measurement conditions, indicated in text). As an example, we made 10 calibration plots in the range 0.010-10 mM using the same electrode, obtaining a RSD value of 5.2\% (the same electrode was used 10 times). In other series we made calibration plots using 10 different electrodes from the same batch (each electrode was used only one time), obtaining RSD 2.7\%. When using electrodes from different batches RSD about 3\% were obtained.

Calibration plots are shown in Figure 7B and D. The figures are shown only for a narrow concentration window. A sensitive cathodic signal with fast response time is observed. The sensitivity of the sensor for the amperometric determination at $+140 \mathrm{mV}, \mathrm{S} 140$, is around $0.08 \mathrm{~mA} \mathrm{mM}^{-1}$. 
Calibration plots are shown in Figure 7B and D. The figures are shown only for a narrow concentration window. A sensitive cathodic signal with fast response time is observed. The sensitivity of the sensor for the amperometric determination at $+140 \mathrm{mV}, \mathrm{S} 140$, is around $0.08 \mathrm{~mA} \cdot \mathrm{mM}^{-1}$.

The presented calibration plots begin at $5 \mu \mathrm{M}(0.005 \mathrm{mM}$ in Figure $7 \mathrm{~B})$. However, we verified that can be extended up to $3 \mu \mathrm{M}$ of $\mathrm{K}_{2} \mathrm{Cr}_{2} \mathrm{O}_{7}$. The difference between the amperometric signal recorded at $3 \mu \mathrm{M}$ and the signal presented in $\mathrm{H}_{2} \mathrm{SO}_{4}$ at $\mathrm{pH} 1$ in the absence of $\mathrm{K}_{2} \mathrm{Cr}_{2} \mathrm{O}_{7}$, is three times higher than the electronic noise observed in the absence of $\mathrm{K}_{2} \mathrm{Cr}_{2} \mathrm{O}_{7}$. Thus, the estimated limit of quantification, $\mathrm{LOQ}$, is $3 \mu \mathrm{M}$. The observed limit of detection, LOD, is about $1.0-1.5 \mu \mathrm{M}$, where the difference of time-averaged signals is slightly higher than the noise. These values of LOQ and LOD may have a 3-5\% of variation with the particular considered sensor and the considered batch.

\subsection{Quality parameters of the amperometric signal at $-380 \mathrm{mV}$}

Figure 8 (A and C) also shows amperometric recordings and (B and D) calibration plots obtained from the same experiment exposed in Figure 7 but now at $-380 \mathrm{mV}$ working potential. Similarly, a fast cathodic signal is obtained at the electrode. Figure $8 \mathrm{C}$ shows a broader concentration range. The sensitivity of the electrode is around $0.1 \mathrm{~mA} \cdot \mathrm{mM}^{-1}$.

Figure 9 illustrates the behavior of the sensor showing an amperometric recording obtained from experiments performed by increasing concentration of $\mathrm{K}_{2} \mathrm{Cr}_{2} \mathrm{O}_{7}$ in an extended concentration range $(10 \mu \mathrm{M}-40 \mathrm{mM})$. The response is quite linear, although sensitivity slightly decreases at concentrations above $20 \mathrm{mM}$. The rise time is about 2-3 s in the whole concentration range. Stabilization of the signal may take 3-5 min after injection, depending of the analyte concentration, as discussed in the previous section. The sensitivity of the electrode is clearly enough to unambiguously detect concentration steps of 1-2 $\mu \mathrm{M}$ of $\mathrm{Cr}(\mathrm{VI})$, with a limit of detection (LOD) of $1 \mu \mathrm{M}$.

\subsection{Stability, reproducibility and potentiality for environmental applications}

The short-term stability of the electrodes was evaluated by analyzing the sensitivity of ten calibrations performed using the same sensor. The resulting relative standard deviation (RSD) of $5.2 \%$ demonstrates the robustness of the electrode even though they are disposables. The effect of using different surfaces was also checked by evaluating the sensitivity of ten corresponding calibration plots, resulting in an RSD of $2.7 \%$. Concerning long-term stability, after 6 months of storage in air, at room temperature and in darkness, the response of the electrode remained at around $100 \%$ of the original one. 


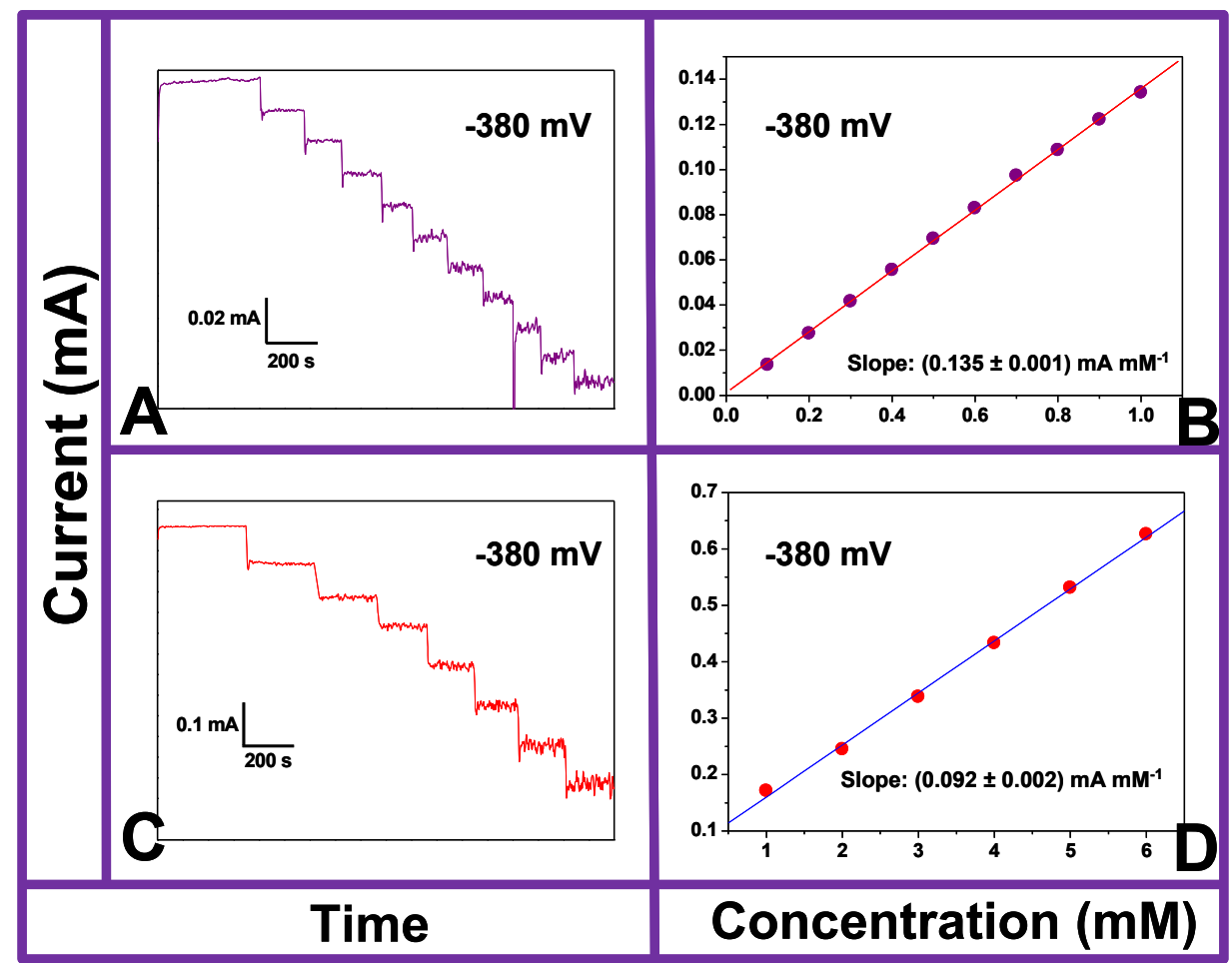

Figure 8. Amperometric recordings (A and $C$ ) and calibration plot (B and D) obtained from experiments performed by successive additions of $\mathrm{Cr}(\mathrm{VI})$, at $\mathbf{- 3 8 0} \mathrm{mV}$. Supporting electrolyte: $\mathrm{H}_{2} \mathrm{SO}_{4}$ pH: 1.0. Reference electrode: $\mathbf{A g} / \mathbf{A g C l}$. Counter electrode: graphite.

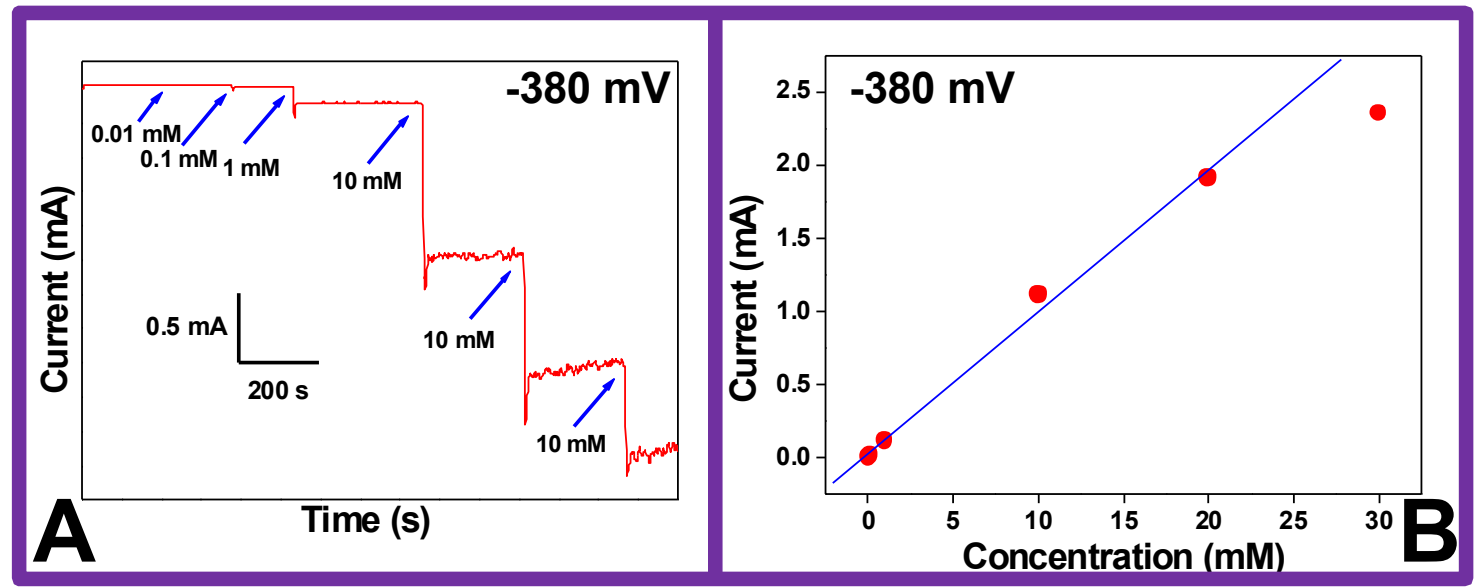

Figure 9. Amperometric recordings (A) and calibration plot (B) obtained from experiments performed by successive additions of different $\mathrm{Cr}(\mathrm{VI})$ concentration, at -380 . Supporting electrolyte: $\mathrm{H}_{2} \mathrm{SO}_{4} \mathrm{pH}$ : 1.0. Reference electrode: $\mathbf{A g} / \mathbf{A g C l}$. Counter electrode: graphite. 
Concerning the effect of oxygen in the media, it has been reported [46] that the oxygen reduction in $\mathrm{H}_{2} \mathrm{SO}_{4}$ starts at potentials more negative than $-500 \mathrm{mV}$ for carbon platforms. Therefore, in the case of the present device, the oxidation of the solvent starts at more negative potentials and thus does not interfere with the studied signals (in fact oxygenated and deoxygenated solutions present the same profile). Therefore, nitrogen purge is not required for the developed sensors, which is a very important result concerning to possible in situ determinations for environmental monitoring, where nitrogen sparging is not possible or impractical.

The results with epoxy-based dense conductor and dielectric show similar, but lower and noisier response (see supplement S5). As the active electrode material was the same, this poorer performance was attributed degradation of the electrode by excessive hightemperature exposure during hardening of the dielectric $\left(150^{\circ} \mathrm{C} 2 \mathrm{~h}\right)$, with loss of plasticizer or DTPA being the most likely mechanisms. This also illustrates the need for further study of the impact of the electrode formulation (resin, plasticizer, type of carbon, ionophore) on the electrochemical behavior.

\subsection{Comparison with other sensors and methods for $\mathrm{Cr}(\mathrm{VII})$ detection}

A table for comparison of the performance between sensors developed by different authors is presented (Table 2), indicating range of $\mathrm{pH}, \mathrm{LOD}, \mathrm{LOQ}$, concentration range for linear response and sensitivity. When comparing with other sensors reported by authors which use amperometric or potentiometric detection, it can be observed the very good limit of detection, extended range for linear response, and high sensitivity for working at $\mathrm{pH} 1$ of the presented sensors. For instance, in comparison with the $\mathrm{Cr}(\mathrm{VI})$ sensor developed by Hallam et al. [34], the sensors presented here have twice the sensitivity, a much larger dynamic range (two orders of magnitude) with a similar limit of detection. On the other hand, when using selective adsorbents, masking agents or formation of complexes, the LOD can be in the range of $\mathrm{nM}$ in the case of electro- chemical methods also (e.g. for stripping voltammetry, see Table 2). In the case of spectroscopic methods, including Atomic Absorption Spectroscopy (AAS) and ICP-tandems, the LODs can range from nM to $\mu \mathrm{M}$ depending on the preconcentration technique used. If no preconcentration technique is used, the LODs are typically about $0.1-1 \mu \mathrm{M}$. 
Table 2. Comparison of quality parameters between $\mathrm{Cr}(\mathrm{VI})$ sensors developed by different authors.

\begin{tabular}{|c|c|c|c|c|c|c|}
\hline $\begin{array}{l}\text { Authors/ } \\
\text { reference }\end{array}$ & $\begin{array}{l}\text { Electrode/ } \\
\text { surface }\end{array}$ & $\begin{array}{l}\text { pH of } \\
\text { work } \\
\text { or } \\
\text { range }\end{array}$ & LOD & LOQ & $\begin{array}{l}\text { Concentration } \\
\text { range for } \\
\text { linear response }\end{array}$ & Sensitivity \\
\hline Present work & Graphite-SPE & $\mathrm{pH} 1$ & $1 \mu \mathrm{M}$ & $3 \mu \mathrm{M}$ & $3 \mu \mathrm{M}-10 \mathrm{mM}$ & $0.08 \mathrm{~mA} / \mathrm{mM}$ \\
\hline Bergamini et al. [30] & Modified-SPE & $\mathrm{pH} 2$ & $0.05 \mu \mathrm{M}$ & $0.1 \mu \mathrm{M}$ & $0.1 \mu \mathrm{M}-0.15 \mathrm{mM}$ & $1.1 \mathrm{~mA} / \mathrm{mM}$ \\
\hline $\begin{array}{l}\text { Sanchez-Moreno et } \\
\text { al. [31] }\end{array}$ & Graphite-epoxy & $\mathrm{pH} 3$ & $0.6 \mu \mathrm{M}$ & $1 \mu \mathrm{M}$ & $1 \mu \mathrm{M}-10 \mathrm{mM}$ & $\begin{array}{l}60 \mathrm{mV} / \mathrm{dec} \\
\text { (potentiometry) }\end{array}$ \\
\hline Fiol et al. [32] & $\begin{array}{l}\text { Graphite } \\
\text { powder, epoxy } \\
\text { resin }\end{array}$ & $\mathrm{pH} 2-3$ & $2 \mu \mathrm{M}$ & $20 \mu \mathrm{M}$ & $20 \mu \mathrm{M}-3 \mathrm{mM}$ & $\begin{array}{l}61 \mathrm{mV} / \mathrm{dec} \\
\text { (potentiometry) }\end{array}$ \\
\hline Svancara et al. [33] & Modified-CPE & $\mathrm{pH} 1$ & $0.05 \mu \mathrm{M}$ & $0.5 \mu \mathrm{M}$ & $0.5-50 \mu \mathrm{M}$ & $\begin{array}{l}\text { (stripping } \\
\text { preconcentration) }\end{array}$ \\
\hline Hallam et al. [34] & SPE-graphite & $\mathrm{pH} 1$ & $0.4 \mu \mathrm{M}$ & $2 \mu \mathrm{M}$ & $2-20 \mu \mathrm{M}$ & $0.03 \mathrm{~mA} / \mathrm{mM}$ \\
\hline $\begin{array}{l}\text { Domímguez-Renedo } \\
\text { et al. [35] }\end{array}$ & Modified-SPE & $\mathrm{pH} 3-6$ & $0.4 \mu \mathrm{M}$ & $0.4 \mu \mathrm{M}$ & $0.4-30 \mu \mathrm{M}$ & $\begin{array}{l}0.02 \mathrm{~mA} / \mathrm{mM} \\
\text { (differential } \\
\text { pulsed } \\
\text { voltammetry) }\end{array}$ \\
\hline Welch et al. [13] & Gold electrode & $\mathrm{pH} 1-3$ & $4 \mu \mathrm{M}$ & $0.1 \mathrm{mM}$ & $0.1-1.5 \mathrm{mM}$ & $0.05 \mathrm{~mA} / \mathrm{mM}$ \\
\hline Neto et al. [27] & $\begin{array}{l}\text { Bismuth film } \\
\text { electrode }\end{array}$ & $\mathrm{pH} 4.6$ & $0.3 \mathrm{nM}$ & $1 \mathrm{nM}$ & - & $\begin{array}{l}9.53 \mu \mathrm{A} / \mathrm{nM} \\
\text { (stripping } \\
\text { preconcentration) }\end{array}$ \\
\hline Lin et al. [28] & $\begin{array}{l}\text { Bismuth film } \\
\text { electrode }\end{array}$ & pH 6 & $0.3 \mathrm{nM}$ & $1 \mathrm{nM}$ & $5-50 \mathrm{nM}$ & $\begin{array}{l}0.07 \mu \mathrm{A} / \mathrm{nM} \\
\text { (stripping } \\
\text { preconcentration) }\end{array}$ \\
\hline
\end{tabular}

\section{Conclusions}

The present work shows the excellent quality parameters for $\mathrm{Cr}(\mathrm{VI})$ detection using screen printed sensors in extremely low $\mathrm{pH}$ values. The most relevant characteristics of the sensing plat- forms proposed here are the remarkable sensitivities, the extended dynamic range, and the low detection limit. Remarkably, the sensor do not display signal when a $\mathrm{Cr}$ (III) salt is dissolved at $\mathrm{pH} 1$ (thus, it can discriminate $\mathrm{C}(\mathrm{VI})$ from $\mathrm{Cr}(\mathrm{III})$ ), but is sensitive to local formation of $\mathrm{Cr}$ (III) at the surface when $\mathrm{Cr}$ (VI) is reduced on the electrode. The developed sensors are very efficient for using in bioremediation processes control since they have an excellent performance at low $\mathrm{pH}$ values. Oxygen removal is not required, which is an essential issue when working in the field. The combination of such an excellent analytical 
performance with the enormous possibilities offered by simple, low-cost disposable screenprinted electrodes are highly promising for addressing the requirements of environmental chemical analysis.

\section{Acknowledgements}

Financial support was received from the University of Buenos Aires (UBACyT 2012-2015, 20020110100098), Ministry of Science, Technology and Innovations of Argentina (PICT 2010-2829 and PICT 2011-0377) and from the CODEV Seed Money Programme of the École Polytechnique Fédérale de Lausanne (EPFL), Switzerland. The authors thank Mr. Matthias Garcin, EPFL, for help in fabricating the samples, the Center of Advanced Microscopy (CMA), School

of Sciences, University of Buenos Aires, for obtaining the SEM images, and are also grateful to TIMCAL for kindly donating the KS4 graphite powder.

\section{Appendix A. Supplementary data}

Supplementary material related to this article can be found, in the online version, at http://dx.doi.org/10.1016/j.snb.2014.01.013.

\section{References}

[1] Q. Wu, Y. Qu, X. Li, D. Wang, Chromium exhibits adverse effects at environmental relevant concentrations in chronic toxicity assay system of nematode Caenorhabditis elegans, Chemosphere 87 (2012) 1281-1287.

[2] A.K. Shanker, B. Venkateswarlu, Chromium: environmental pollution, health effects and mode of action, in: Encyclopedia of Environmental Health, 2011, pp. 650-659.

[3] Z.-H. Li, P. Li, T. Randak, Evaluating the toxicity of environmental concentrations of waterborne chromium (VI) to a model teleost, Oncorhynchus mykiss: a comparative study of in vivo and in vitro, Comp. Biochem. Physiol. Part C: Toxicol. Pharmacol. 153 (2011) 402-407.

[4] E. Kiliç, R. Puig, G. Baquero, J. Font, S. Çolak, D. Gürler, Environmental optimization of chromium recovery from tannery sludge using a life cycle assessment approach, J. Hazard. Mater. 192 (2011) 393-401.

[5] J.B. Vincent, The bioinorganic chemistry of chromium (III), Polyhedron 20 (2001) 126.

[6] J. Kotás, Z. Stasicka, Chromium occurrence in the environment and methods of its speciation, Environ. Pollut. 107 (2000) 263-283. 
[7] M. Gagneten, J.C. Paggi, Effects of heavy metal contamination ( $\mathrm{Cr}, \mathrm{Cu}, \mathrm{Pb}, \mathrm{Cd})$ and eutrophication on zooplankton in the Lower Basin of the Salado River (Argentina), Water Air Soil Pollut. (2009) 317-334.

[8] Guidance for Drinking Water Quality, Recommendations, vol. 1, second ed., WHO, Geneva, 1993, pp. 45-46.

[9] G. Hanrahan, D.G. Patil, J. Wang, Electrochemical sensors for environmental monitoring: design, development and applications, J. Environ. Monit. 6 (2004) 657664.

[10] F.J. Alguacil, M. Alonso, F. Lopez, A. Lopez-Delgado, Uphill permeation of Cr(VI) using Hostarex A327 as ionophore by membrane-solvent extraction processing, Chemosphere 72 (2008) 684-689.

[11] F.J. Alguacil, A.G. Coedo, M.T. Dorado, A.M. Sastre, Uphill permeation of chromium (VI) using Cyanex 921 as ionophore across an immobilized liquid membrane, Hydrometallurgy 61 (2001) 13-19.

[12] M. Tuzen, M. Soylak, Multiwalled carbon nanotubes for speciation of chromium in environmental samples, J. Hazard. Mater. 147 (2007) 219-225.

[13] C.M. Welch, O. Nekrassova, R.G. Compton, Reduction of hexavalent chromium at solid electrodes in acidic media: reaction mechanism and analytical applications, Talanta 65 (2005) 74-80.

[14] P.E. Rosi, S.A. Miscoria, D.L. Bernik, R.M. Negri, Customized design of electronic noses placed on top of air-lift bioreactors for in situ monitoring the off-gas patterns, Bioprocess Biosyst. Eng. 35 (2012) 835-842.

[15] K. Bredberg, H.T. Karlsson, O. Holst, Reduction of vanadium(V) with Acidithiobacillus ferrooxidans and Acidithiobacillus thiooxidans, Bioresour. Technol. 92 (2004) 93-96.

[16] R.M. Gargarello, D. Di Gregorio, H. Huck, J. Fernandez Niello, G. Curutchet, Reduction of uranium(VI) by Acidithiobacillus thiooxidans and Acidithiobacillus ferrooxidans, Hydrometallurgy 104 (2010) 529-532.

[17] R.T. Pflaum, L.C. Howick, The chromium-diphenylcarbazide reaction, J. Am. Chem. Soc. 78 (19) (1956) 4862-4866.

[18] P.F. Urone, Stability of colorimetric reagent for chromium, s-diphenylcarbazide in various solvents, Anal. Chem. 27 (8) (1955) 1354-1355.

[19] Y. Inoue, T. Sakai, H. Kumaguai, Simultaneous determination of $\mathrm{Cr}(\mathrm{III})$ and $\mathrm{Cr}(\mathrm{VI})$ by ion chromatography with inductively coupled plasma mass spectrometry, J. Chromatogr. A 706 (1995) 127-136. 
[20] P. Liang, T.Q. Shi, H.B. Lu, Z.C. Jiang, B. Hu, Adsorption of Cr(VI) and speciation of $\mathrm{Cr}(\mathrm{VI})$ and $\operatorname{Cr}(\mathrm{III})$ in aqueous solutions using chemically modified chitosan, Spectrochim. Acta B 58 (2003) 1709-1714.

[21] P. Wu, H. Chen, G. Cheng, X. Hou, Exploring surface chemistry of nano-TiO(2) for automated speciation analysis of $\mathrm{Cr}(\mathrm{III})$ and $\mathrm{Cr}(\mathrm{VI})$ in drinking water using flow injection and ET-AAS detection, J. Anal. At. Spectrom. 24 (2009) 1098-1104.

[22] M.T. Siles Cordero, E. Vereda Alonso, A. Garcia de Torres, J.M. Cano Pavon, Development of a new system for the speciation of chromium in natural waters and human urine samples by combining ion exchange and ETA-AAS, J. Anal. At. Spectrom. 19 (2004) 398-403.

[23] Y.L. Chang, S.J. Jiang, Determination of chromium species in water samples by liquid chromatography-inductively coupled plasma-dynamic reaction cell- mass spectrometry, J. Anal. Atom. Spectrom. 16 (2001) 858.

[24] V. Gómez, M.P. Callao, Chromium determination and speciation since 2000, Trends Anal. Chem. 25 (2006) 1006-1015.

[25] M.S. Tehrani, P.A. Azar, S.W. Husain, F. Shafaei, Dispersive liquid-liquid microextraction of $\mathrm{Cr}(\mathrm{VI})$ in water and hair samples by electrothermal atomic absorption spectrometry, Asian J. Chem. 22 (2010) 6302-6310.

[26] C. Diniz Pereira, J.G. Techy, E. Moreira Ganzarollib, S.P. Quináia, Chromium fractionation and speciation in natural waters, J. Environ. Monit. 14 (2012) 15591564.

[27] E.O. Jorge, M.M. Rocha, I.T.E. Fonseca, M.M.M. Neto, Studies on the stripping voltammetric determination and speciation of chromium at a rotating-disc bismuth film electrode, Talanta 81 (2010) 556-564.

[28] L. Lin, N.S. Lawrence, S. Thongngamdeea, J. Wang, Y. Lin, Catalytic adsorptive stripping determination of trace chromium (VI) at the bismuth film electrode, Talanta 65 (2005) 144-148.

[29] M. Grabarczyk, Speciation analysis of chromium by adsorptive stripping voltammetry in tap and river water samples, Electroanalysis 20 (2008) 2217-2222.

[30] M.F. Bergamini, D.P. dos Santos, M.V.B. Zanoni, Development of a voltammetric sensor for chromium(VI) determination in wastewater sample, Sens. Actuators B 123 (2007) 902-907.

[31] R.A. Sánchez-Moreno, M.J. Gismera, M.T. Sevilla, J.R. Procopio, Evaluation of solid-state platforms for chromium (VI) potentiometric sensor development, Anal. Bioanal. Chem. 397 (2010) 331-338. 
[32] N. Fiol, F. de la Torre, P. Demeyere, A. Florido, I. Villaescusa, Vegetable wastebased sensors for metal ion determination, Sens. Actuators B 122 (2007) 187-194.

[33] I. Svancara, P. Foret, K. Vytras, A study on the determination of chromium as chromate at a carbon paste electrode modified with surfactants, Talanta 64 (2004) 844-852.

[34] P.M. Hallam, D.K. Kampouris, R.O. Kadara, N. Jenkinson, C.E. Banks, Graphite screen printed electrodes for the electrochemical sensing of chromium(VI), Analyst 135 (2010) 1947-1951.

[35] O. Domínguez-Renedo, L. Ruiz-Espelt, N. García-Astorgano, M.J. Arcos- Martínez, Electrochemical determination of chromium(VI) using metallic nanoparticlemodified carbon screen-printed electrodes, Talanta 76 (2008) 854-858.

[36] N. Serra, T. Maeder, P. Ryser, Piezoresistive effect in epoxy-graphite composites, Sens. Actuators A 186 (2012) 198-202.

[37] B. Jiang, P. Muralt, P. Heeb, A.J. Santis-Alvarez, M. Nabavi, D. Poulikakos, P. Niedermann, T. Maeder, A micro heater platform with fluid channels for testing microsolid oxide fuel cell components, Sens. Actuators B 175 (2012) 218-224.

[38] F. Gruet, F. Vecchio, C. Affolderbach, Y. Pétremand, N.F. de Rooij, T. Maeder, G. Mileti, A miniature frequency-stabilized VCSEL system emitting at $795 \mathrm{~nm}$ based on LTCC modules, Opt. Lasers Eng. 51 (2013) 1023-1027.

[39] T. Maeder, S. Miscoria, C. Jacq, P. Ryser, R.M. Negri, Screen-printed electrochemical chromium (VI) sensing electrodes for effluent bioremediation monitoring, Proc. Eng. 47 (2012) 1303-1306.

[40] G.A. Rivas, S.A. Miscoria, J. Desbrières, G.D. Barrera, New biosensing plat- forms based on the layer-by-layer self-assembling of polyelectrolytes on Nafion/carbon nanotubes-coated glassy carbon electrodes, Talanta 71 (2007) 270-275.

[41] S.A. Miscoria, J. Desbrières, G.D. Barrera, P. Labbè, G.A. Rivas, Glucose biosensor based on the layer-by-layer self-assembling of glucose oxidase and chi- tosan derivatives on a thiolated gold surface, Anal. Chim. Acta 578 (2006) 137-144.

[42] K. Pitt, Handbook of Thick Film Technology, 2nd ed., Electrochemical Publications, Isle of Man, 2005.

[43] Y.V. Moissev, N.A. Khalturinskii, G.E. Zaikov, The mechanism of the acid-catalysed hydrolysis of polysaccharides, Carbohydr. Res. 51 (1976) 39-54.

[44] R. Bucci, A.D. Magrì, A.L. Magrì, A. Napoli, On the reaction of iron(III) with chromium(III)-DTPA chelating agent, Polyhedron 19 (2000) 2421-2425. 
[45] Y. Li, H. Xue, Determination of $\mathrm{Cr}(\mathrm{III})$ and $\mathrm{Cr}(\mathrm{VI})$ species in natural waters by catalytic cathodic stripping voltammetry, Anal. Chim. Acta 448 (2001) 121-134.

[46] M.D. Rubianes, G.A. Rivas, Carbon nanotubes paste electrode, Electrochem. Commun. 5 (2003) 689-694.

\section{Biographies}

Silvia Alejandra Miscoria graduated at Universidad Nacional de la Patagonia "San Juan Bosco", Argentina, as Biochemist and continued a $\mathrm{PhD}$ in Chemistry working in biosensors designs. Since 2010 is carrying out a post-doc in the Instituto de Quimica Fisica de Materiales, Ambiente y Energía (INQUIMAE), Universidad de Buenos Aires in chemistry sensors designs.

Caroline Jacq graduated with a Master thesis in materials science from the Institut Supérieur des Matériaux du Mans (ISMANS), and is working as a researcher at the Ecole Polytechnique Fédérale de Lausanne (EPFL) since 2001. Her main research interests concern the development and study of novel lead-free thick-film materials systems and their application to medical devices.

Thomas Maeder graduated at the Ecole Polytechnique Fédérale de Lausanne (EPFL) in materials science, and continued with a $\mathrm{PhD}$ in piezoelectric thin films, then a post-doc at IBM Rüschlikon in single-crystal conductive oxides. He now heads the thick-film technology group at the EPFL, where current areas of interest are thick-film and LTCC technology for advanced sensor, packaging, biomedical and harsh-environment applications.

R. Martín Negri graduated in physics at the University of Buenos Aires (UBA) where made a $\mathrm{PhD}$ in Chemistry. He is member of the research career of CONICET (Argentina) and Professor at School of Science-UBA, heading a group in the field of materials science and sensors development. 


\title{
Screen-printed electrodes for electroanalytical sensing of chromium (VI) in strong acid media.
}

\author{
(Supplementary material) \\ S. A. Miscoria, C. Jacq, T.Maeder, R. M. Negri
}

\section{Contents}

S1. Detailed formulation and processing of the deposited layers

S2. Cross section of the device \& electrode paste structure

S3. Mechanical drawing of the substrate

S4. Structure of the thermoplastic binder - PVB vs. EC

S5. Comparative results with some epoxy-based materials

S6. Additional references for supplements

\section{S1. Detailed formulation and processing of the deposited layers}

Except the thick-film Ag composition (ESL 9912K), all layers were formulated in-house. The detailed formulations of the layers indicated in Table 1 of the main document are given in Table S1, with Table S2 giving the corresponding source materials. This section concerns the main study on the PVB-based materials - see section S5 for epoxy-based compositions.

Due to the requirements for obtaining an appropriate ink rheology for screen printing, the used solvent mix was varied from paste to paste, with DPGME being used as a basis for the dense carbon and dielectric layers, and texanol for the porous carbon composition.

The formulated pastes, after screen printing, were dried for $\sim 10 \mathrm{~min}$ at $100^{\circ} \mathrm{C}$ for intermediate prints (dense and porous carbon electrodes), in order to avoid unnecessary exposure to high temperatures that may degrade the organic materials. Such a drying step proved sufficient for subsequent printing operations. The final drying of the dielectric was slightly more extensive, $\sim 10 \mathrm{~min}$ at $120^{\circ} \mathrm{C}$, in order to complete solvent removal.

\section{S1.1. Dense carbon conductor ink}

For the dense carbon conductor (\#374-12), the conductive filler volume fraction (calculated to be $\sim 34 \%$ after drying) is typically well above the percolation threshold [S1-S3], yet the matrix (PVB + ATBC) is still able to fill the voids (Fig. S3, layer B). This ink was used in all samples in the basic study.

A modest level of plasticizer (ATBC:PVB 1:3) was included to yield a toughened matrix. The obtained sheet resistance was around $300 \Omega$, for a $\sim 20 \mu \mathrm{m}$ thick film. 


\section{S1.2. Porous carbon electrode inks}

Four electrode inks were prepared, with zero (\#375-2), 2\% (\#375-4), 5\% (\#375-3) and $\sim 8 \%$ (\#375-5) wt\% DTPA after drying. As DTPA essentially does not dissolve in the solvent mix used for PVB, it is first prepared as a $\sim 15 \mathrm{wt} \%$ solution in DMSO, and this solution is then added to the ink.

To allow large-area contact between the electrode and the sensed medium, these compositions should be bicontinuous, i.e. with percolation of both the pores (i.e. open porosity) and of the conductive graphite filler (Fig. S2, layer A). Therefore, a much lower amount of "matrix" phase (PVB \& ATBC) was used, with the calculated volume fraction of graphite after drying being $\sim 70 \%$. The presence of open porosity was checked qualitatively with a felt pen - the ink from the pen was rapidly absorbed into the electrode layers, while it remained as a droplet on the surface of the dense conductor or dielectric films described in sections S1.2 and S1.3.

As there was a concern that the binder would form an impermeable thin film on the graphite, a much higher level of plasticiser was used than for the dense layer to nevertheless facilitate diffusion (ATBC:PVB 1:1), yielding a quite soft electrode analogous to carbon paste ones [S4].

Note that, while good results were obtained with these electrodes in the present work, their development was still quite empirical, and many points should be clarified, especially:

- Where and in which form is DTPA found? What is the optimal level, and how is it best applied for maximum activity?

- What is the distribution of the matrix phase, around the necks between the graphite particles and possibly as a continuous / semicontinuous film on the particles' surface?

- In what way do the matrix properties (plasticity, affinity for water) affect the electrochemical behavior?

- What is the optimal form of the carbon filler?

\section{S1.3. Dielectric ink}

Two protective dielectric inks were formulated by including a waxy compound, cetanol in the PVB matrix, which yields so-called "hot-melt" compositions similar to those used in our previous studies $[\mathrm{S} 3 ; \mathrm{S} 5 ; \mathrm{S} 6]$ :

- At high temperature (during the solvent evaporation phase, $\sim 120^{\circ} \mathrm{C}$ ), the material remains liquid, because the wax is liquid and act as a solvent for PVB at this temperature.

- Upon cooling to room temperature, progressive crystallization of the wax is observed, which yields a tough, impermeable and essentially defect-free layer.

- Upon heating up the layer again, the material reverts to a viscous liquid, as the waxy phase remelts and redissolves the PVB binder; pinholes and scratches may be "annealed out" this way.

The particular dielectric inks were formulated so that crystallization of the wax also happens in the original paste (in general, this depends on the wax content and the solvent), 
in order to impart suitable rheology. A first series of samples (with 5\% DTPA in the working electrode) was prepared with the first dielectric (\#380-6), with the formulation later adjusted (\#380-12) for the other samples, in order to achieve better printability. This had no observed effect on behavior, as both dielectrics formed defect-free protective layers. Actually, flowability in the hot state was somewhat too good, so, in future versions, some of the wax should be replaced with a mineral filler to achieve a more balanced compromise between flowability and resolution.

Table S1: Thick-film compositions used in the fabrication of the SPEs, PVB system (see Fig. 1), quantities in 'solvent', 'matrix', and 'other' columns given in weight \% of paste, and DTPA content in porous carbon (left column) given in weight \% of PVB + ATBC + KS4.

\begin{tabular}{|c|c|c|c|c|c|}
\hline Layer & $\begin{array}{l}\text { Code } \\
\#\end{array}$ & $\begin{array}{l}\text { Solvent } \\
(\%)\end{array}$ & $\begin{array}{l}\text { Matrix } \\
(\%)\end{array}$ & $\begin{array}{l}\text { Other } \\
(\%)\end{array}$ & $\begin{array}{c}\text { Solids } \\
(\%)\end{array}$ \\
\hline $\begin{array}{l}\text { Dense carbon } \\
\text { (B) }\end{array}$ & $374-12$ & $\begin{array}{l}\text { 39.4 DPGME } \\
19.6 \mathrm{BG} \\
\text { 6.9 DEPD }\end{array}$ & $\begin{array}{l}12.3 \mathrm{PVB} \\
4.1 \mathrm{ATBC}\end{array}$ & $17.7 \mathrm{KS} 4$ & 34.1 \\
\hline $\begin{array}{l}\text { Porous carbon } \\
\text { (A) }\end{array}$ & $375-2$ & 64.3 Texanol & $\begin{array}{l}3.4 \text { PVB } \\
3.4 \text { ATBC }\end{array}$ & $28.9 \mathrm{KS} 4$ & 35.7 \\
\hline$+4.7 \% D T P A$ & $375-3$ & $\begin{array}{l}52.9 \text { Texanol } \\
\text { 9.4 DMSO }\end{array}$ & $\begin{array}{l}2.8 \text { PVB } \\
2.8 \text { ATBC }\end{array}$ & $\begin{array}{l}30.4 \mathrm{KS} 4 \\
1.7 \mathrm{DTPA}\end{array}$ & 37.7 \\
\hline$+2.0 \% D T P A$ & $375-4$ & $\begin{array}{c}59.5 \text { Texanol } \\
4.3 \text { DMSO }\end{array}$ & $\begin{array}{l}3.3 \text { PVB } \\
3.3 \text { АTBC }\end{array}$ & $\begin{array}{l}28.8 \mathrm{KS} 4 \\
0.7 \mathrm{DTPA}\end{array}$ & 36.2 \\
\hline$+8.5 \%$ DTPA & $375-5$ & $\begin{array}{l}\text { 42.1 Texanol } \\
\text { 18.5 DMSO }\end{array}$ & $\begin{array}{l}1.8 \text { PVB } \\
1.9 \text { ATBC }\end{array}$ & $\begin{array}{l}32.6 \mathrm{KS} 4 \\
3.0 \mathrm{DTPA}\end{array}$ & 39.4 \\
\hline Dielectrics (D) & $380-6$ & $\begin{array}{l}\text { 33.3 DPGME } \\
\text { 23.7 DEPD }\end{array}$ & $\begin{array}{l}11.3 \text { PVB } \\
2.8 \text { ATBC }\end{array}$ & 28.9 Cetanol & \\
\hline & $380-12$ & $\begin{array}{l}\text { 36.0 DPGME } \\
\text { 18.1 DEPD }\end{array}$ & 10.9 PVB & $\begin{array}{c}32.0 \text { Cetanol } \\
3.0 \mathrm{C} 18 \mathrm{E} 2\end{array}$ & 45.9 \\
\hline
\end{tabular}


Table S2: Detailed information for all chemical products used in this study (see also Table S1).

†Roles $: \mathrm{Sv}=$ solvent $; \mathrm{MB}=$ matrix binder $; \mathrm{MP}=$ matrix plasticiser $; \mathrm{MW}=$ matrix wax $; \mathrm{C}=$ conductive filler ; I = ionophore. *Sources: S-A = Sigma-Aldrich, Buchs, Switzerland; TIMCAL = TIMCAL, Bodio, Switzerland.

\begin{tabular}{|c|c|c|c|c|}
\hline Designation & Description & CAS & Source* & Role $\dagger$ \\
\hline ATBC & Acetyl tributylcitrate & $77-90-7$ & S-A W308005 & MP \\
\hline BG & 2,3-butanediol (butylene glycol) & $513-85-9$ & S-A 18980 & $\mathrm{~Sv}$ \\
\hline C18E2 & $\begin{array}{l}\text { Diethylene glycol stearyl ether, } \\
\text { PEG-2 stearyl ether, steareth-2 }\end{array}$ & $9005-00-9$ & S-A 16006 & MW \\
\hline Cetanol & Cetyl alcohol, 1-hexadecanol & $36653-82-4$ & S-A W255408 & MW \\
\hline DEPD & 2,2-diethyl-1,3-propanediol & $115-76-4$ & S-A D100005 & $\mathrm{Sv}$ \\
\hline DMSO & Dimethylsulfoxide & $67-68-5$ & S-A W387509 & $\mathrm{Sv}$ \\
\hline DPGME & Dipropylene glycol methyl ether & $34590-94-8$ & S-A 484253 & $\mathrm{~Sv}$ \\
\hline DTPA & $\begin{array}{l}\text { DTPA: Diethylenetriamine- } \\
\text { pentaacetic acid }\end{array}$ & $67-43-6$ & S-A 32319 & I \\
\hline KS4 & Graphite $(90 \%<4 \mu \mathrm{m})$ & $7782-42-5$ & TIMCAL KS4 & $\mathrm{C}$ \\
\hline PVB & Polyvinylbutyral (see S3) & $27360-07-2$ & S-A 418439 & MB \\
\hline Texanol & $\begin{array}{l}\text { 2,2,4-trimethyl-1,3-pentanediol } \\
\text { monoisobutyrate }\end{array}$ & $25265-77-4$ & S-A 538221 & $\mathrm{~Sv}$ \\
\hline
\end{tabular}




\section{S2. Cross section of the device \& electrode paste structure}

The schematic cross sections (not to scale, thickness expanded for better legibility) of the working and counter electrode areas, as well as of the Ag lines below the dielectric, are shown in Fig. S1 (see also Both electrode structures are similar, except for the porous layer (A) deposited on the working electrode only. The silver (Ag) conductor lines insure high "long-range" conduction, and are chemically separated from the solution by the dense layer (B), which also serves as a "local" conductor. Deposition of Ag as two separate strips for the working electrode allows checking that the resin-carbon composites are conductive (percolation between graphite particles).

The dense (B) and porous resin-carbon composites (A) differ in the volume ratio between the organic matrix and the graphite filler (Fig. S2):

- The dense layer is formulated so that the graphite filler has good electrical percolation, but there is still enough matrix material for filling the volume between the filler particles.

- In contrast, the porous layer is greatly "starved" of matrix material; the matrix therefore merely fills the necks between the particles, leaving an open porosity allowing access to the studied medium (aqueous solution). The matrix here has two main roles: 1) hold the particles together, thereby ensuring a bicontinuous electrode + porosity structure; 2) contain, if required, the ionophore, in our study DTPA. Depending on the wetting properties of the matrix on the particles and on diffusion mechanisms through the matrix, on expects the electrochemical sensing behavior to vary considerably. 
(a)

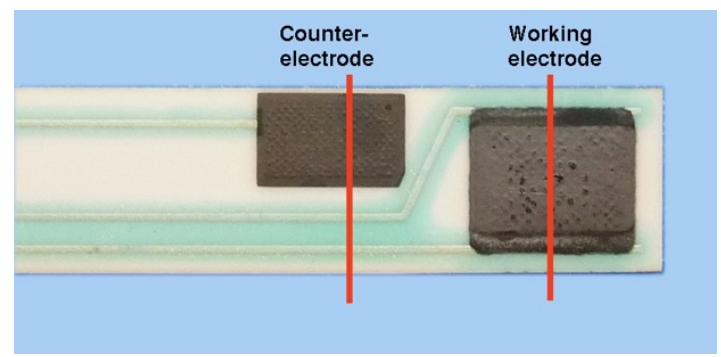

(b)

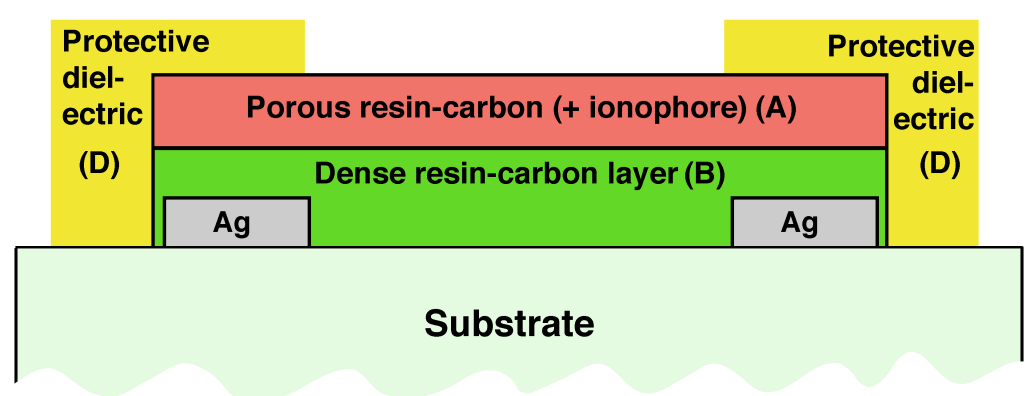

(c)

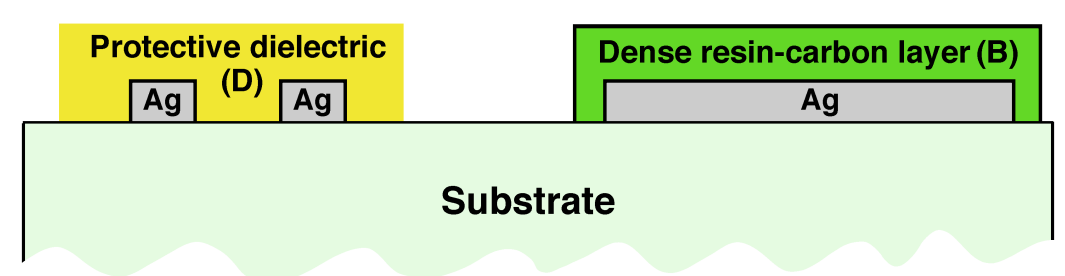

Fig. S1. Schematic cross sections: a) position on the sensor; b) working electrode; c) counter-electrode \& Ag conductor lines below dielectric.

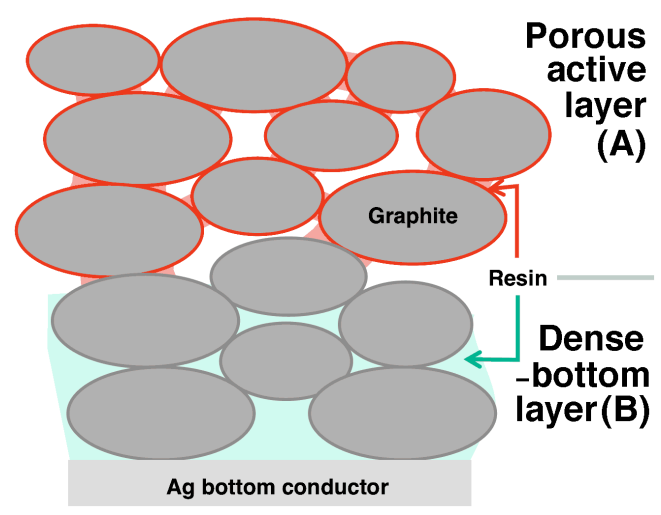

Fig. S2. Compared schematic structures of the dense (bottom) and porous (top) binder-graphite composites. Both are bound by a similar resin material, but, in the active layer, the resin has a low volume fraction to ensure open porosity, and is highly plasticised to allow diffusion. 


\section{S3. Mechanical drawing of the substrate}

As usual in thick-film technology [25], the samples are processed in batches consisting of $101.6 \mathrm{~mm}$ (edge length) square ceramic alumina substrates, which are laser scored according to the drawing in Fig. S3. After the printing steps, the sensors may be easily individualized by breaking off along the scoring lines.

While alumina was used in this study because it was readily available, the sensors may be easily transferred to suitable organic substrates such as polyethylene terephthalate (PET) films, epoxy-glass printed circuit board (PCB) material, etc.

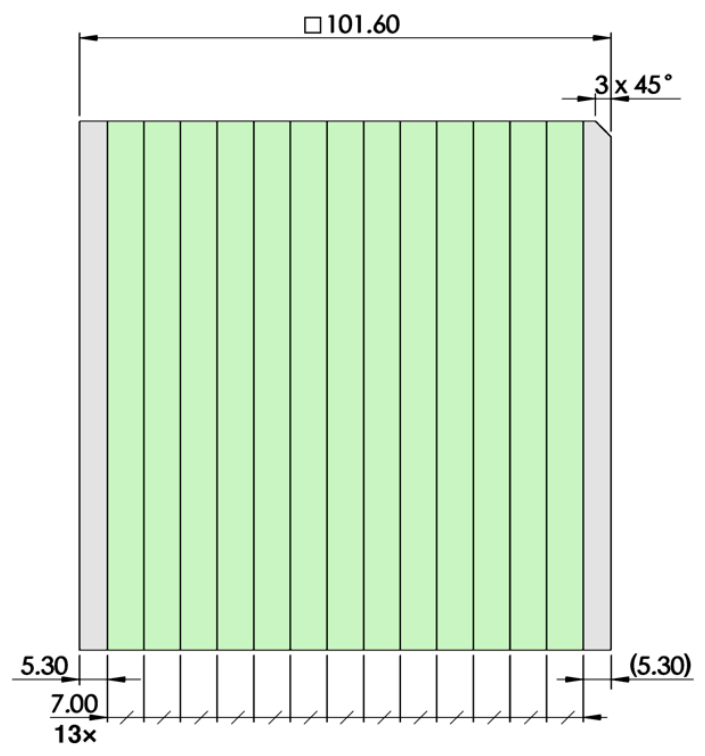

Fig. S3. Mechanical drawing (dimensions in $\mathbf{~ m m}$ ) of the alumina substrates, each yielding 13 sensors of $101.6 \times 7.0 \mathrm{~mm}^{2}$ area (in green), with the grey border zones being used for handling and printing registration.

\section{S4. Structure of the thermoplastic binder - PVB vs. EC}

The structure of the polyvinylbutyral (PVB) binder used in this study is compared to that of ethylcellulose (EC), a "classical" binder used in thick-film pastes, in Fig. S4. It should be noted that neither designation is exactly accurate, as both binders are actually random copolymers, but this does not affect the structure of the backbone - although it does affect the selection of appropriate solvents, plasticizers and waxes (section S1).

As can be seen in Fig. S4, PVB has polyvinyl (straight carbon chain) backbone that is essentially insensitive to de-polymerization in acidic media, although some detachment of the substituting groups may occur in service. On the other hand, the backbone of EC bases on glycosidic bonds, which are acid sensitive, resulting in cleavage and progressive depolymerization at low $\mathrm{pH}$ levels [26,S7-S9]. In contrast, PVB has been successfully applied as a binder for $\mathrm{pH}$ sensors stable down to at least $\mathrm{pH} \sim 2$ [S10].

Therefore, PVB, although it was somewhat more difficult to work with in terms of achieving the right paste rheology, was chosen over EC in this study. Our grade was 
specified, as a measure of chain length, by its Ostwald viscosity of $\sim 7 \mathrm{mPa} \cdot \mathrm{s}$ at $20^{\circ} \mathrm{C}$ for a $6 \%$ by weight solution in anhydrous methanol [S11].

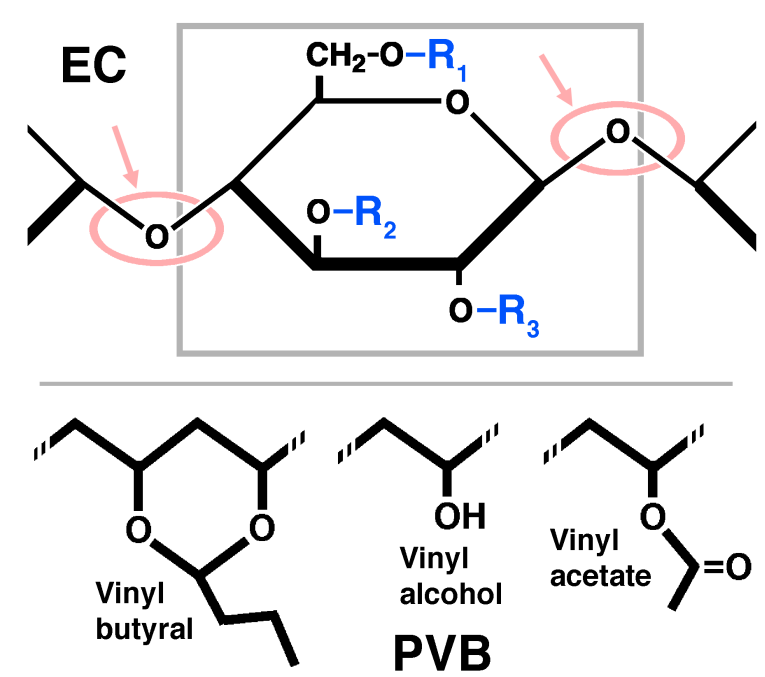

Fig. S4. Structure of EC (common binder used in thick-film inks) vs. PVB, with the acid-sensitive glycosidic links in EC marked by ovals \& arrows. Both "PVB" and "EC" are actually random copolymers; EC: typical total substitution of $R_{1}, R_{2}, R_{3}(H$ in cellulose, forming hydroxyl groups with the adjacent oxygen) by ethyl (-CH$-\mathrm{CH}_{3}$, forming ether bonds) $\sim 2.5 / 3(83 \%)$, often expressed in terms of ethoxyl weight fraction $(\sim 48 \%)$ [S7-S9]; PVB: nominal for our grade $\sim 80 \%$ butyral $+19 \%$ alcohol + $1 \%$ acetate.

\section{S5. Comparative studies with some epoxy-based materials}

An alternate series of samples was manufactured with two materials, the dense carbon conductor and protective dielectric, being substituted with compositions based on an epoxy (EP) resin (see overview in Table S3). Note that the active layer material was the same as in the main study, i.e PVB-based, with here a single DTPA content ( 5\%, \#375-3, Table S1).

The EP resin was Epo-Tek 377 (Epoxy Technology, USA), in line with some of our previous studies [19,S1,S2]. Having a low viscosity, it was not diluted with solvents.

The formulation of the EP-based materials was analogous to that of their PVB-based counterparts; the same TIMCAL KS4 graphite filler was used at similar volume fraction for the dense conductor, and, for the protective dielectric, a mineral filler $\left(\mathrm{Al}_{2} \mathrm{O}_{3}\right.$ powder $)$ was used instead of a wax. On the other hand, the hardening cycle for each EP layer was much more extensive: $2 \mathrm{~h}$ at $150^{\circ} \mathrm{C}$, instead of $10 \mathrm{~min}$ at $100 / 120^{\circ} \mathrm{C}$ for the PVB-based layers.

Some results are shown for this alternate system in Fig. S5. The current response is lower for these alternative devices, with the amperometric traces also being much noisier. As the active material was nominally the same, the origin of the reduced activity presumably lies with a degradation of its properties, brought about by the modified materials system. The fundamental cause is deemed to be the much more extensive hardening cycle of the EPbased dielectric, to which the active material is also subjected. A few degradation mechanisms may be envisioned for the active electrode: 
- Reaction of the active layer with the dielectric. This is not thought to be an important factor, as the dielectric (see Fig. S1) was not observed to spread significantly.

- Thermal degradation of the PVB matrix. Although the observed onset of degradation of PVB by thermogravimetric analysis (TGA, fast heating at $\sim 10 \mathrm{~K} / \mathrm{min}$ ) is $\sim 250-300^{\circ} \mathrm{C}$ [S12,S13], some thermo-oxidative degradation is possible at $150^{\circ} \mathrm{C}$ given the long dwell time: some visible yellowing was found after $10 \mathrm{~min}$ at $160^{\circ} \mathrm{C}$ [S14]. However, an important alteration of the resin was otherwise not found at this temperature.

- Plasticizer loss. Evaporative mass loss of plasticizer from PVB was found to start at $\sim 200^{\circ} \mathrm{C}$ for fast heating during TGA [S13], and the vapor pressure of ATBC at $170^{\circ} \mathrm{C}$ is indicated to be $107 \mathrm{~Pa}$ [S15]. Therefore, significant evaporation of ATBC at $150^{\circ} \mathrm{C}$ is plausible, given the long $2 \mathrm{~h}$ dwell.

- Loss of DTPA. DTPA could possibly react with the plasticized PVB matrix or the underlying EP resin, or undergo degradation itself, as its stability in static heating is reported to be limited to $\sim 120^{\circ} \mathrm{C}$ [S16].

The most plausible mechanisms behind the degraded response therefore seem to be loss of plasticizer by evaporation and reaction / degradation of DTPA. Degradation is therefore not thought to directly involve the presence of EP-based materials, but indirectly, through the extensive curing cycle required for the particular resin we used. This highlights the need to limit the thermal budget during production, which is also important if one wishes to manufacture the sensors on organic substrates.

Table S3: Comparison of main PVB-based \& alternative series $(† 5 \%$ DTPA in active layer).

\begin{tabular}{lll}
\hline Layer & Basic PVB-based system & Comparative system \\
\hline Ag conductor tracks \& contact pads & ESL 9912K & ESL 9912K \\
Dense carbon layer & PVB - ATBC - KS4 & EP - KS4 \\
Porous active carbon layer $\dagger$ & PVB - ATBC - KS4 - DTPA & PVB - ATBC - KS4 - DTPA \\
Protective dielectric & PVB - ATBC - cetanol & EP - $\mathrm{Al}_{2} \mathrm{O}_{3}$ \\
Dielectric, final curing thermal cycle & $120^{\circ} \mathrm{C} 10 \mathrm{~min}$ & $150^{\circ} \mathrm{C} 2 \mathrm{~h}$ \\
\hline
\end{tabular}




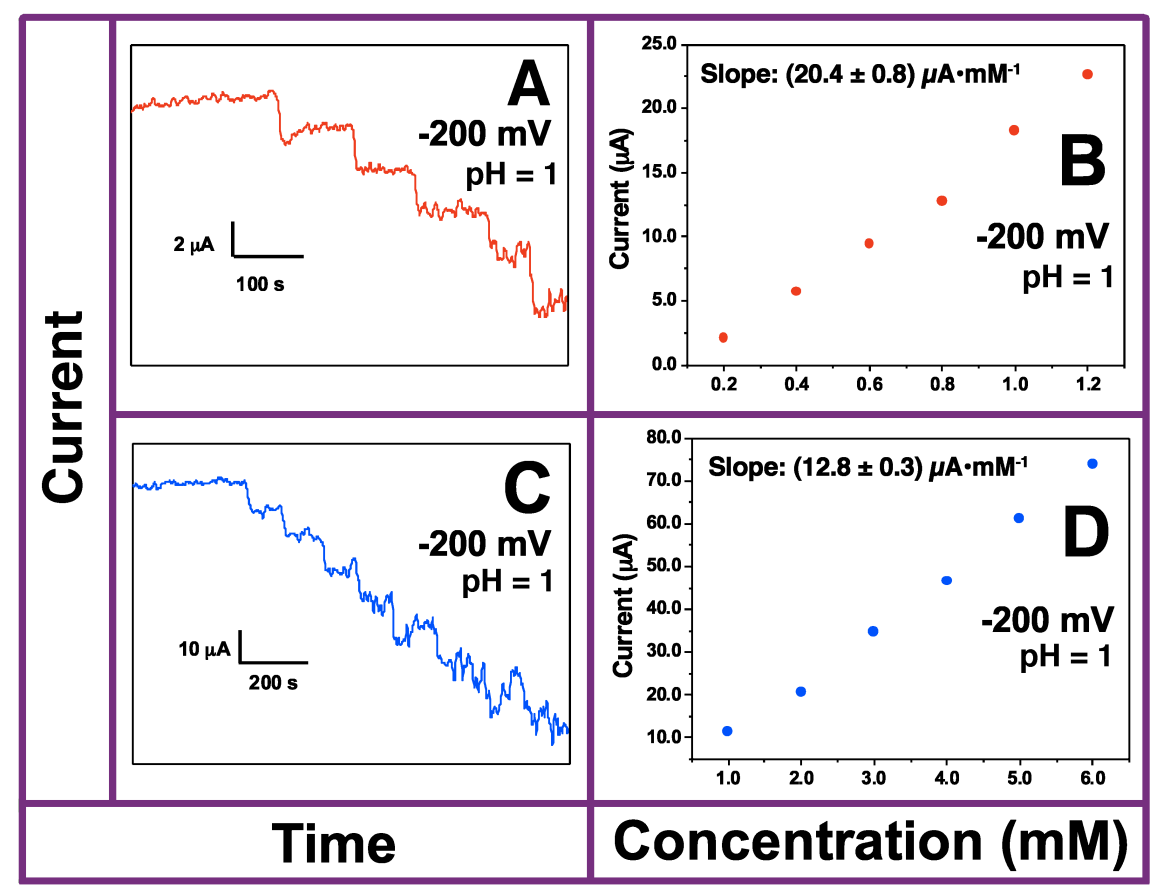

Fig. S5. Amperometric recordings (A and $C$ ) and calibration plots ( $B$ and $D)$ obtained from experiments performed by successive additions of $0.2 \mathrm{mM}(\mathrm{A}$ and $\mathrm{B}$ ) and $1.0 \mathrm{mM}(\mathrm{C}$ and $\mathrm{D}) \mathrm{Cr}$ (VI), at $-200 \mathrm{mV}$. Supporting electrolyte: $\mathrm{H}_{2} \mathrm{SO}_{4}, \mathrm{pH}=1.0$. In this case a Pt counter electrode was used.

\section{S6. Additional references for supplements}

[S1] N. Serra, T. Maeder, P. Lemaire, P. Ryser, "Formulation of composite resistive pastes for fabrication of micro-heaters", Sensors and Actuators A 162 (2), 367-372, 2010.

[S2] N. Serra, "Epoxy-graphite resistive composites: Formulation, characterization and applications", thesis no 5346, EPFL, Switzerland, 2012.

[S3] T. Maeder, C. Jacq, L. Ammon, P. Ryser, "Tuneable PTC effect in polymer-waxcarbon composite resistors", Proceedings, XXXVII International Conference of IMAPS Poland Chapter, Cracow (PL), in press, 2013.

[S4] K. Vitřas, I. Švancara, R. Metelka, "Carbon paste electrodes in electroanalytical chemistry", Journal of the Serbian Chemical Society 74 (10), 1021-1033, 2009.

[S5] T. Maeder, B. Jiang, F. Vecchio, C. Jacq, P. Ryser, P. Muralt, "Lamination of LTCC at low pressure and moderate temperature using screen-printed adhesives", Proceedings, $8^{\text {th }}$ International Conference on Ceramic Interconnect and Ceramic Microsystems Technologies (CICMT), Erfurt (DE), 348-352, 2012.

[S6] T. Maeder-T, J.L. Mietta, M.M. Ruiz, C. Jacq, G. Jorge, P. Ryser, R.M. Negri, "Magnetically tuneable thermoplastic resistive composites", Proceedings, Electronic Devices and Systems (EDS), IMAPS-CS International Conference, Brno (CZ), XIXVIII, 2013. 
[S7] G. S. Rekhi, S. S. Jambhekar, Ethylcellulose - a polymer review, Drug Development and Industrial Pharmacy 21 (1995) 61-77.

[S8] T.G. Majewicz, T.J. Podlas, Cellulose ethers, Kirk-Othmer Encyclopedia of Chemical Technology, Wiley \& Sons (USA) 5, 445-466, 2000.

[S9] "ETHOCEL ethylcellulose polymers technical handbook", product information No. 192-00818-0905 X AMS, Dow Chemical, Midland (USA), 2005.

[S10] E. Gill, A. Arshak, K. Arshak, O. Korostynska, "pH sensitivity of novel PANI/PVB/PS3 composite films", Sensors 7 (2007) 3329-3346.

[S11] "Butvar polyvinyl butyral resin - Properties \& uses", Solutia, Inc. (USA), Pub. No. $2008084 \mathrm{E}, 2007$.

[S12] N.R. Gurak, P.L. Josty, R.J. Thompson, "Properties and uses of synthetic emulsion polymers as binders in advanced ceramics processing", American Ceramic Society Bulletin 66 (1987) 1495-1497.

[S13] A.K. Dhaliwal, J.N. Hay, "The characterization of polyvinyl butyral by thermal analysis", Thermochimica Acta 391 (2002) 245-255.

[S14] Měřínská-D Tupý-M Kašpárková-V Popelková-J Zvoníček-J Pištěk-D Svoboda-P, "Degradation of plasticized PVB during reprocessing by kneading", Macromolecular Symposia 286 (1), 107-115, 2009.

[S15] "Citroflex A-4 materials safety datasheet (MSDS)", Vertellus, USA, 2011.

[S16] M.F. Gargallo Esteban, M.C.P. Vizcaíno F. González-Vílchez, "Comparative thermal study of some aminopolycarboxylic chelating agents", Thermochimica Acta 62 (1983) 267-278. 